\title{
Using Differences in Knowledge Across Neighborhoods to Uncover the Impacts of the EITC on Earnings
}

\section{Citation}

Chetty, Raj, John N Friedman, and Emmanuel Saez. 2013. "Using Differences in Knowledge Across Neighborhoods to Uncover the Impacts of the EITC on Earnings." American Economic Review 103 (7) (December): 2683-2721. doi:10.1257/aer.103.7.2683.

\section{Published Version}

doi:10.1257/aer.103.7.2683

\section{Permanent link}

http://nrs.harvard.edu/urn-3:HUL.InstRepos:27304827

\section{Terms of Use}

This article was downloaded from Harvard University's DASH repository, and is made available under the terms and conditions applicable to Other Posted Material, as set forth at http:// nrs.harvard.edu/urn-3:HUL.InstRepos:dash.current.terms-of-use\#LAA

\section{Share Your Story}

The Harvard community has made this article openly available.

Please share how this access benefits you. Submit a story.

\section{Accessibility}




\title{
Using Differences in Knowledge Across Neighborhoods to Uncover the Impacts of the EITC on Earnings
}

\author{
By Raj Chetty, John N. Friedman, And Emmanuel SAez*
}

\begin{abstract}
We estimate the impacts of the Earned Income Tax Credit on labor supply using local variation in knowledge about the EITC schedule. We proxy for EITC knowledge in a ZIP code with the fraction of individuals who manipulate reported self-employment income to maximize their EITC refund. This measure varies significantly across areas. We exploit changes in EITC eligibility at the birth of a child to estimate labor supply effects. Individuals in high-knowledge areas change wage earnings sharply to obtain larger EITC refunds relative to those in low-knowledge areas. These responses come primarily from intensive-margin earnings increases in the phase-in region.
\end{abstract}

A widely accepted view in the literature on labor supply is that income taxation leads to much larger responses on the extensive margin (participation) than on the intensive margin (hours of work or earnings conditional on working). This finding has important implications for understanding the macroeconomic impacts of taxation and for the optimal design of tax and transfer policies (e.g., Piketty and Saez 2012). In this paper, we show that prior studies of short-run responses to tax reforms may have underestimated the importance of intensive-margin responses. Recent work suggests that a lack of knowledge about changes in the tax code and other adjustment frictions can lead to sluggish adjustment of labor supply, especially on the intensive margin (Chetty 2012). We develop a new research design that overcomes these frictions, and find intensivemargin responses to taxation that are similar in magnitude to previously documented extensive-margin responses.

Our research design is based on a simple idea: individuals with no knowledge of a tax policy's marginal incentives behave as they would in the absence of the policy. ${ }^{1}$

\footnotetext{
* Chetty: Department of Economics, Harvard University, Littauer Center, 1805 Cambridge Street, Cambridge, MA 02138, and National Bureau of Economic Research (e-mail: chetty@fas.harvard.edu). Friedman: Harvard Kennedy School, Taubman Center 356, 79 John F. Kennedy Street, Cambridge, MA 02138, and National Bureau of Economic Research (e-mail: john_friedman@harvard.edu). Saez: University of California, 530 Evans Hall \#3880, Berkeley, CA 94720 and National Bureau of Economic Research (e-mail: saez@econ.berkeley.edu). We thank Joseph Altonji, Josh Angrist, Richard Blundell, David Card, Alex Gelber, Adam Guren, Steven Haider, Nathaniel Hilger, Joseph Hotz, Hilary Hoynes, Lawrence Katz, Kara Leibel, Bruce Meyer, Sendhil Mullainathan, Alan Plumley, Laszlo Sandor, Karl Scholz, Jesse Shapiro, Monica Singhal, Seth Stephens-Davidowitz, Danny Yagan, anonymous referees, and numerous seminar participants for helpful discussions and comments. The tax data were accessed through contract TIRNO-09-R-00007 with the Statistics of Income (SOI) Division at the US Internal Revenue Service. The results in this paper do not necessarily reflect the official views of the Internal Revenue Service (IRS). Itzik Fadlon, Peter Ganong, Sarah Griffis, Jessica Laird, Shelby Lin, Heather Sarsons, Michael Stepner, and Clara Zverina provided outstanding research assistance. Financial support from the Lab for Economic Applications and Policy at Harvard, the Center for Equitable Growth at Berkeley, and the National Science Foundation is gratefully acknowledged.

${ }^{1}$ As we discuss in Section I below, this equivalence holds in the absence of income effects. With income effects, our technique recovers compensated elasticities under the assumption that uninformed individuals believe that the tax credit is a lump-sum subsidy.
} 
Hence, we can identify the causal effect of a policy by comparing behavior across cities that differ in knowledge about the policy but are otherwise comparable. We apply this method to analyze the impacts of the Earned Income Tax Credit, the largest meanstested cash transfer program in the United States, on earnings behavior and inequality. We exploit fine geographical heterogeneity across ZIP codes by using data from U.S. population tax records spanning 1996-2009, which include over 75 million unique EITC eligible individuals with children and 1 billion observations on their annual earnings.

Our empirical analysis proceeds in two steps. First, we develop a proxy for local knowledge about the marginal rate structure of the EITC. ${ }^{2}$ Ideally, one would measure knowledge directly using data on individuals' perceptions of the EITC schedule. Lacking such data, we proxy for knowledge using the extent to which individuals manipulate their reported income to maximize their EITC refunds by reporting self-employment income. Self-employed tax filers have a propensity to report income exactly at the first kink of the EITC schedule, the point that maximizes net tax refunds (Saez 2010). We show that the degree of "sharp bunching" by self-employed individuals at the first kink varies substantially across ZIP codes. For example, 6.5 percent of EITC claimants in Chicago, IL in 2008 are self-employed and report earnings exactly at the refund-maximizing level, compared with 0.6 percent in Rapid City, SD. Consistent with knowledge diffusion, bunching spreads across the country over time: the degree of bunching is almost three times larger in 2009 than in 1996.

The key assumption needed to use sharp bunching as a proxy for knowledge about the EITC schedule is that individuals in low-bunching neighborhoods believe that the EITC has no impact on their marginal tax rates. We present two pieces of evidence supporting this assumption. First, we show that the spatial heterogeneity in bunching appears to be driven by differences in knowledge about the first kink of the EITC schedule. We find that those who move from low-bunching to high-bunching neighborhoods report incomes that yield larger EITC refunds on average after they move. In contrast, those who move from high-bunching to low-bunching neighborhoods experience no change in average EITC refunds after they move, consistent with learning and memory. Moreover, we find that bunching is highly correlated with predictors of information diffusion, such as the density of EITC recipients and availability of professional tax preparers. Second, we show that individuals in low-bunching areas are unaware not just about the refund-maximizing kink but about the EITC schedule more broadly. In particular, when individuals become eligible for a much larger EITC refund after having their first child, the distribution of their reported self employment income remains virtually unchanged in low-bunching areas. ${ }^{3}$

In the second half of the paper, we identify the causal impact of the EITC on wage earn-

\footnotetext{
${ }^{2}$ Throughout the paper, we use the term "knowledge" or "information" about the EITC to refer to knowledge about the program's marginal incentive structure rather than awareness of the program's existence. Note that IRS outreach efforts focus on increasing take-up rather than disseminating information about the details of the non-linear marginal rate structure of the schedule.

${ }^{3}$ If individuals in low-bunching areas have some knowledge of the EITC schedule, our approach would underestimate earnings responses to the EITC. Hence, measurement error in our proxy for local knowledge would work against our finding that the EITC has significant intensive-margin earnings impacts.
} 
ings by using neighborhoods with low levels of sharp bunching among the self-employed (i.e., low-knowledge neighborhoods) as counterfactuals for behavior in the absence of the EITC. Unlike self-employment income, wage earnings are double reported by employers to the IRS on W-2 forms. Misreporting of wage earnings is therefore minimal, and changes in wage earnings are driven by real choices such as hours of work (Andreoni, Erard, and Feinstein 1998, Chetty et al. 2012).

We find that the wage earnings distribution exhibits more mass around the refundmaximizing EITC plateau in neighborhoods with high self-employed sharp bunching, indicating that the EITC affects labor supply choices in high-knowledge areas. To account for potential differences across neighborhoods that are not caused by the EITC, we exploit the fact that individuals with no children are essentially ineligible for the EITC, thus forming a natural control group. Using event studies, we show that wage earnings in low-bunching and high-bunching neighborhoods track each other closely in the years prior to child birth. However, when a first child is born, and the household becomes EITC-eligible, wage earnings distributions immediately become much more concentrated around the EITC plateau in high-bunching ZIP codes, leading to larger EITC refunds in those areas. This result is robust to allowing for ZIP-level fixed effects, so that the impacts of the EITC on wage earnings are identified purely from within-area variation over time in the degree of knowledge about the schedule. Moreover, the birth of a third child - which has no impact on EITC refunds in the years we study - does not generate differential changes in earnings across areas.

Comparing changes in earnings around child birth in high vs. low knowledge neighborhoods, we estimate that earnings responses to the EITC increase total refund amounts by approximately 5 percent on average across the U.S. Approximately 75 percent of the increase in EITC refunds due to behavioral responses comes from individuals who change the amount they earn rather than whether they work or not, showing that the EITC has substantial intensive margin impacts. We find significant differences between the program's impacts on earnings in the phase-in and phase-out regions. The increases in EITC refunds due to behavioral responses are commensurate to an intensive-margin earnings elasticity of 0.31 in the phase-in region and an intensive-margin earnings elasticity of 0.14 in the phase-out region on average in the U.S. The phase-in and phase-out elasticities are 0.84 and 0.29 in areas in the top decile of EITC knowledge. Approximately 70 percent of the increase in EITC refunds due to behavioral responses in highknowledge areas comes from increases in earnings in the phase-in region, with only 30 percent coming from reductions in earnings in the phase-out region.

Finally, we use our estimates to non-parametrically identify the impacts of the EITC on the income distribution in the U.S. We find that the EITC has raised net incomes at the low end of the income distribution significantly with limited work disincentive effects. The fraction of EITC-eligible wage-earners below the poverty line falls from 31.3 percent without the EITC to 21.4 percent by mechanically including EITC payments (holding earnings and reported incomes fixed). The fraction below the poverty line falls further to 21.0 percent once earnings responses to the EITC are taken into account. If knowledge about the EITC schedule were to increase to the level observed in the highest 
decile of bunching, the poverty rate would fall further to 20.2 percent.

Our results build on a large literature on the impacts of the EITC on labor supply surveyed by Hotz and Scholz (2003), Eissa and Hoynes (2006), and Meyer (2010). Several studies have shown that the EITC clearly increases labor force participation the extensive-margin response (e.g., Eissa and Liebman 1996, Meyer and Rosenbaum 2001, Grogger 2003, Hotz and Scholz 2006, Gelber and Mitchell 2012). However, evidence on intensive-margin responses is much more mixed (e.g., Meyer and Rosenbaum 1999, Bollinger, Gonzalez, and Ziliak 2009, Rothstein 2010). Prior studies, which focus on short-run changes in behavior around EITC reforms, may have detected extensivemargin responses because knowledge about the increased return to working diffused more quickly than knowledge about how to optimize on the intensive margin. Surveys show that the knowledge that working can yield a large tax refund - which is all one needs to know to respond along the extensive margin - is much more widespread than knowledge about the non-linear marginal incentives created by the EITC (Liebman 1998, Ross Phillips 2001, Romich and Weisner 2002, Smeeding, Ross Phillips, and O'Connor 2002, Maag 2005). ${ }^{4}$ This pattern of knowledge diffusion is consistent with a model of rational information acquisition, as re-optimizing in response to a tax reform on the extensive margin has first-order (large) benefits, whereas reoptimizing on the intensive margin has second-order (small) benefits (Chetty 2012). Intensive-margin responses may therefore take more time to emerge. Thus, the common wisdom that intensivemargin responses are smaller than extensive-margin responses may be an artifact of the short-run research designs used in prior work.

Our analysis also contributes to the literature on estimating behavioral responses from non-linearities in the budget set and bunching at kink points (e.g., Hausman 1981, Saez 2010, Chetty et al. 2011, Kleven and Waseem 2012). As wage-earners cannot control earnings perfectly, the impact of taxes on the wage earnings distribution is diffuse and does not produce visible bunching at kinks. As a result, traditional non-linear budget set methods would again lead to the conclusion that taxation does not generate intensivemargin responses. We uncover wage-earners' diffuse real earnings responses by exploiting the ability to non-parametrically identify sharp bunching among the self-employed to develop a counterfactual.

The remainder of the paper is organized as follows. Section I presents a stylized model to formalize our research design. Section II provides background about the EITC and the data we use. Section III documents heterogeneity across neighborhoods in selfemployed sharp bunching and shows that this heterogeneity is driven by differences in information. Section IV presents our main results on the effects of the EITC on wage earnings. In Section V, we report elasticity estimates and calculate the impacts of the EITC on income inequality. Section VI concludes. Additional details and results are available in an online appendix and the working paper version (Chetty, Friedman, and Saez 2012).

\footnotetext{
${ }^{4}$ For example, among the 42 families interviewed by Romich and Weisner (2002), 90 percent had heard of the EITC, but only two families knew that they needed to earn a certain amount to maximize their credit.
} 


\section{Model and Research Design}

In this section, we develop a stylized non-linear budget-set model of labor supply and tax compliance to formalize our research design and identification assumptions. We make two simplifications in our derivation. First, we assume that firms have constantreturns-to-scale technologies and pay workers a fixed pre-tax wage of $w$. Second, we abstract from income effects in labor supply by assuming that workers have quasi-linear utility functions. We discuss how these assumptions affect our estimator below.

Setup. Individuals, indexed by $i$, make two choices: labor supply $\left(l_{i}\right)$ and tax evasion $\left(e_{i}\right)$. Let $z_{i}=w l_{i}$ denote true earnings and $\widehat{z}_{i}=z_{i}-e_{i}$ denote reported taxable income. When $\widehat{z}_{i}<K$, workers face a marginal tax rate of $\tau_{1}<0$ (a subsidy for work). For earnings above $K$, individuals face a marginal tax rate of $\tau_{2}>0$ (a clawback of the subsidy). Let $\tau=\left(\tau_{1}, \tau_{2}\right)$ denote the vector of marginal tax rates. ${ }^{5}$

There are two types of workers: tax compliers and non-compliers. Non-compliers face zero cost of evasion and always choose $e_{i}$ to report $\widehat{z}_{i}=K$ and maximize their tax refunds (when they know the tax schedule, see below). Compliers face an infinite cost of altering their reported taxable income and hence always set $e_{i}=0$.

Individuals have quasi-linear utility functions $u\left(C_{i}, l_{i}, \alpha_{i}\right)=C_{i}-h\left(l_{i}, \alpha_{i}\right)$ over a numéraire consumption good $C_{i}$ and labor supply $l_{i}$. The parameter $\alpha_{i}$ captures skill or preference heterogeneity across agents. Individuals cannot set $l_{i}$ exactly at their utilitymaximizing level because of frictions and rigidities in job packages. Because of these frictions, the empirical distribution of true earnings $F(z)$ exhibits diffuse excess mass around the refund-maximizing kink $K$ rather than sharp bunching at the kink $K$. As a result, non-linear budget-set methods (e.g., Hausman 1981) and the bunching estimator of Saez (2010) cannot identify the impact of taxes on earnings behavior.

Our estimator exploits geographic heterogeneity for identification. To model such heterogeneity, assume that there are $N$ cities of equal size in the economy, indexed by $c=1, \ldots, N$. Workers cannot move to a different city. Cities differ in their residents' knowledge about the tax credit for exogenous reasons (e.g., the structure of local networks or population density). In city $c$, a fraction $\lambda_{c}$ of workers are aware of the marginal incentives $\tau_{1}$ and $\tau_{2}$ created by the tax credit. ${ }^{6}$ The remainder of the workers optimize as if $\tau_{1}=\tau_{2}=0$ (i.e., $\boldsymbol{\tau}=\mathbf{0}$ ). Cities may differ in the distribution of skills $\alpha_{i}$, denoted by $G_{c}\left(\alpha_{i}\right)$, and in the fraction of non-compliers, $\theta_{c}$. Let $F_{c}(z \mid \tau)$ be the distribution of earnings in city $c$ with a tax system $\tau$.

Identifying Tax Policy Impacts. Our objective is to characterize the impact of the tax credit, as it is currently perceived by agents, on the aggregate earnings distribution:

$$
\Delta F=F(z \mid \boldsymbol{\tau} \neq \mathbf{0})-F(z \mid \boldsymbol{\tau}=\mathbf{0}) .
$$

\footnotetext{
${ }^{5}$ This simplifies the actual EITC schedule shown in Figure 1, which has a plateau region and two kinks. The case with one kink captures the key concepts underlying our research design.

${ }^{6}$ To simplify notation, we assume that $\lambda_{c}$ is the same for compliers and non-compliers. If knowledge varies across the types, the estimator in (3) identifies the treatment effect of interest under the two assumptions below if $\lambda_{c}$ is interpreted as the average level of knowledge across all individuals in each city.
} 
The first term in this expression is the observed distribution of true earnings in the population given current knowledge of the tax credit and rates of non-compliance. ${ }^{7}$ The second term is the unobserved counterfactual outcome without taxes. This counterfactual distribution can be identified by studying cities with no knowledge about the tax system $\tau$. In the absence of income effects, earnings decisions in these cities $\left(\lambda_{c}=0\right)$ are identical to behavior with no taxes at all:

$$
F_{c}\left(z \mid \boldsymbol{\tau} \neq \mathbf{0}, \lambda_{c}=0\right)=F_{c}\left(z \mid \boldsymbol{\tau}=\mathbf{0}, \lambda_{c}=0\right)
$$

To use cities with $\lambda_{c}=0$ as counterfactuals, we first need to measure the degree of knowledge of marginal incentives $\lambda_{c}$ in each city. We do so by taking advantage of the fact that we observe both reported income $\widehat{z}_{i}$ and true wage earnings $z_{i}$ in our data. The fraction of individuals in city $c$ who report taxable income $\widehat{z}_{i}$ exactly at the kink, which we denote by $\phi_{c}$, is equal to the product of local knowledge about the tax code and non-compliance rates: $\phi_{c}=\theta_{c} \lambda_{c}$. Hence, the rate of sharp bunching at the kink $\phi_{c}$ is a noisy proxy for the degree of knowledge $\lambda_{c}$. To identify areas with $\lambda_{c}=0$, we make the following assumption.

Assumption 1 [Tax Knowledge]. Individuals in neighborhoods with no sharp bunching at the kink have no knowledge of the policy's marginal incentives and perceive $\boldsymbol{\tau}=\mathbf{0}$ : $\phi_{c}=0 \Rightarrow \lambda_{c}=0$.

In our simple model, Assumption 1 is equivalent to requiring that $\theta_{c}>0$ in all cities, i.e. that all cities have some non-compliers. In this case, a city with no sharp bunching at the kink must be a city in which no one knows about the tax incentives. ${ }^{8}$ More generally, the key assumption underlying our approach is that individuals in areas with no sharp bunching behave on average as if the credit induces no change in their marginal tax rates $(\boldsymbol{\tau}=\mathbf{0})$. If some areas with $\phi_{c}=0$ actually have knowledge about marginal incentives created by the tax code, our approach will understate the impact of tax policy on earnings behavior. While we are unable to directly test Assumption 1, we show that knowledge drives variation in $\phi_{c}$ and that individuals in cities with $\phi_{c} \simeq 0$ behave as if they face no change in taxes $(\boldsymbol{\tau}=\mathbf{0})$ when they become eligible for the tax credit we study.

Under Assumption 1, the empirical distribution of earnings $F_{c}(z)$ in cities with no sharp bunching at the kink $K$ reveals the distribution of earnings in those cities in the absence of taxes:

$$
F_{c}\left(z \mid \boldsymbol{\tau} \neq \mathbf{0}, \phi_{c}=0\right)=F_{c}\left(z \mid \boldsymbol{\tau}=\mathbf{0}, \phi_{c}=0\right) .
$$

Although (2) identifies the necessary counterfactual in cities with no knowledge of the

\footnotetext{
${ }^{7}$ In our model, the real earnings decisions $z_{i}$ of non-compliers are not affected by marginal tax rates because they always set $e_{i}$ to maximize their refund. Hence, a higher fraction of non-compliers leads to smaller real earnings responses on average.

${ }^{8}$ Importantly, Assumption 1 does not require that $\phi_{c}$ is an accurate proxy for differences in knowledge across all cities; it only requires when $\phi_{c}$ is low, knowledge about marginal incentives created by the tax code is low. The second requirement is much weaker and perhaps more plausible.
} 
tax code, estimating the treatment effect in (1) requires that we identify the mean earnings distribution across all cities in the absence of taxes, $F(z \mid \boldsymbol{\tau}=\mathbf{0})=\frac{1}{N} \sum_{c=1}^{N} F_{c}(z \mid \boldsymbol{\tau}=\mathbf{0})$. This leads to the identification assumptions underlying our research design.

Assumption 2a [Cross-Sectional Identification]. Individuals' skills do not vary across cities with different levels of knowledge about the tax credit:

$$
G\left(\alpha_{i} \mid \lambda_{c}\right)=G\left(\alpha_{i}\right) \text { for all } \lambda_{c}
$$

This orthogonality condition requires that cities with different levels of sharp bunching at the kink have comparable earnings distributions. This assumption leads to the following feasible non-parametric estimator for the treatment effect in (1):

$$
\widehat{\Delta F}=F(z \mid \tau)-F\left(z \mid \tau, \phi_{c}=0\right) .
$$

Intuitively, the impact of the tax credit on earnings can be identified by comparing the unconditional earnings distribution with the earnings distribution in cities with no sharp bunching (i.e., no knowledge about the tax credit). This identification strategy requires that the earnings distribution in cities with no bunching is representative of earnings distributions in other cities in the absence of taxes. We can relax this assumption by studying changes in behavior when an individual becomes eligible for the tax credit in panel data. Suppose we observe individuals making labor supply decisions for multiple years. Let $t$ denote the year that an individual becomes eligible for the tax credit. This panel design relies on a weaker "common trends" assumption for identification.

Assumption 2b [Panel Identification]. Changes in skills when an individual becomes eligible for the credit do not vary across cities with different levels of knowledge about the tax credit:

$$
G_{t}\left(\alpha_{i} \mid \lambda_{c}\right)-G_{t-1}\left(\alpha_{i} \mid \lambda_{c}\right)=G_{t}\left(\alpha_{i}\right)-G_{t-1}\left(\alpha_{i}\right) \text { for all } \lambda_{c} .
$$

Under Assumption 2b, we can identify $\Delta F$ using a difference-in-differences estimator that compares earnings distributions across cities before vs. after individuals become eligible for the tax credit:

$$
\widehat{\Delta F}_{D D}=\left[F_{t}(z \mid \tau)-F_{t}\left(z \mid \tau, \phi_{c}=0\right)\right]-\left[F_{t-1}(z \mid \tau)-F_{t-1}\left(z \mid \tau, \phi_{c}=0\right)\right] .
$$

The first term in (4) coincides with the cross-sectional estimator in (3). The second term nets out differences in earnings distributions across cities prior to eligibility for the credit. This estimator requires that skills do not trend differently across cities around the point at which individuals become eligible for the tax credit. We implement the estimator in (4) using the birth of a first child as an instrument for eligibility. Importantly, (4) permits a direct effect of child birth on labor supply as long as the effect does not differ across cities with different amounts of knowledge. Because of such direct effects, we cannot identify $\Delta F$ purely from changes in earnings behavior around the date of eligibility in the full 
population, again making comparisons across cities with different levels of knowledge essential for identification.

Income Effects and Changes in Wage Rates. We now return to the implications of our two simplifying assumptions for our estimator for $\Delta F$. When firms do not have constantreturns-to-scale technologies or have market power, changes in labor supply induced by tax incentives can affect equilibrium wage rates. As a result, the impact of a tax policy on the equilibrium earnings distribution is a function of both labor supply changes and changes in wage rates. The cross-sectional estimator for $\Delta F$ in (3) incorporates any such general equilibrium effects because the earnings distributions in cities with more knowledge about the tax code incorporate both changes in $l_{i}$ and $w_{i}$. The differencein-differences estimator in (4) nets out general equilibrium wage changes if individuals who are eligible and ineligible for the credit are pooled in the same market. ${ }^{9}$

When utility is not quasi-linear, taxes affect behavior through both price and income effects. Because individuals in all cities receive the tax credit we analyze irrespective of their perceptions, our cross-city comparisons essentially net out differences in behavior that arise purely from income effects. Hence, our estimator for $\Delta F$ approximately identifies compensated elasticities in a more general model without quasilinear utility. ${ }^{10}$

\section{Data and Institutional Background}

\section{A. EITC Structure}

The EITC is a refundable tax credit administered through the income tax system. In 2010, 27.4 million tax filers received a total of $\$ 59.6$ billion in EITC payments (Internal Revenue Service 2012, Table 2.5). Eligibility for the EITC depends on total family earnings - wage earnings plus self-employment income - and the number of qualifying dependents. Qualifying dependents for EITC purposes are relatives who are under age 19 (24 for full time students) or permanently disabled, and reside with the tax filer for at least half the year. Note that only one tax filer can claim each eligible child.

Figure 1a shows EITC amounts (on the right y-axis) as a function of earnings for single filers with one vs. two or more qualifying dependents, expressed in real 2010 dollars. This schedule applies to all years in our sample (1996-2009), because the EITC schedule for single filers has remained unchanged (aside from inflation indexation) after a large expansion from 1994-1996. ${ }^{11}$ EITC refund amounts first increase linearly with earnings, then plateau over a short income range, and are then reduced linearly. The phase-in subsidy is 34 percent for taxpayers with one child and 40 percent for those with two or more children; the corresponding phase-out tax rates are 16 percent and 21

\footnotetext{
${ }^{9}$ If both Assumptions 2a and 2b hold one can gauge the magnitude of GE effects by comparing the two estimates. Empirically, we find that the two estimates are quite similar, suggesting that GE wage effects are small; see the working paper version (Chetty, Friedman, and Saez 2012) for further details.

${ }^{10}$ The equivalence is not exact because price effects induce changes in earnings that in turn change the size of the EITC refund that individuals in high bunching areas receive, but this effect is second-order.

${ }^{11}$ The only changes to the EITC that occurred during this period were: (1) a widening of the plateau for married filers, and (2) the introduction of a slightly larger EITC for families with three or more children in 2009. See IRS Publication 596 (Internal Revenue Service 2011) for complete details on program eligibility and rules.
} 
percent. The maximum EITC amount is $\$ 3,050$ for filers with one child and $\$ 5,036$ for those with two or more children.

There is a very small EITC available to filers with no dependents, with a maximum refund of $\$ 457$ in 2010. We ignore this no-child EITC in our analysis and use the term "EITC recipients" to refer exclusively to EITC recipients with at least one qualifying child.

Other aspects of the tax code such as the Child Tax Credit and income taxes can also affect individuals' budget sets. Our estimates incorporate any differences across neighborhoods in knowledge about these other aspects of the tax code as well. However, marginal tax rates in the income range we study are primarily determined by the EITC; the child tax credit and federal income taxes have relatively small effects on incentives, as shown in Appendix Figure 1. We therefore interpret our estimates as the impacts of the EITC on earnings behavior.

\section{B. Sample and Variable Definitions}

We use selected data from the universe of US tax returns spanning 1996-2009, including income tax returns (1040 forms) and third-party information returns (W-2 forms, which are available starting in 1999). We provide a detailed description of how we construct our analysis samples starting from the raw population data in Appendix A. Here, we briefly summarize the key variable and sample definitions. Note that in what follows, the year always refers to the tax year (i.e., the calendar year in which the income is earned).

Variable Definitions. We define income at the household level because the EITC is a function of household income, but conduct our analysis using an individual-level panel to account for potential changes in marital status. We use two earnings concepts. Wage earnings, corresponding to actual earnings $z_{i}$ in our model, is the sum of wage earnings reported on all W-2 forms filed by employers on the primary and secondary filer's behalf. Total earnings, corresponding to reported income $\widehat{z}_{i}$ in our model, is the total amount of earnings used to calculate the EITC, defined as the sum of wage earnings and net selfemployment earnings reported on the 1040 tax returns. We define an individual's ZIP code as the ZIP code from which he filed his year $t$ tax return or the ZIP code to which his W-2 was mailed if he did not file a tax return.

Because W-2's are directly filed by employers, we observe wage earnings for all individuals irrespective of filing status. However, we do not observe total earnings or the number of children for individuals who do not file tax returns, and we do not observe ZIP code for individuals who neither file nor earn wages reported on a W-2. These missing data problems can potentially create selection bias, which we address in our empirical analysis.

Core Sample. Our analysis sample includes individuals who meet all four of the following conditions simultaneously in at least one year between 1996 and 2009: (1) file a tax return as a primary or secondary filer (in the case of married joint filers), (2) have total earnings below \$50,000 (in 2010 dollars), (3) claim at least one child, and (4) have a valid Social Security Number, which is a requirement for EITC eligibility. We impose 
these restrictions to limit the sample to individuals who are likely to be EITC-eligible at least once between 1996 and 2009. We define the total earnings and wage earnings of person-year observations with no reported earnings activity as zero. This procedure yields a balanced panel containing 77.6 million unique individuals and 1.09 billion person-year observations on earnings. Our empirical analysis consists of three different research designs, each of which uses a different subsample of this sample.

Cross-Sectional Analysis Sample. Our first research design compares earnings distributions for EITC claimants across cities in repeated cross-sections. For this analysis, we limit the core sample to person-years in which the individual files a tax return, reports one or more children, has total earnings in the EITC-eligible range, and is the primary filer. By including only primary filers, we eliminate duplicate observations for married joint filers and obtain distributions of earnings that are weighted at the tax return level, which is the relevant weighting for policy analysis.

Movers Sample. Our second research design tracks individuals as they move across neighborhoods. To construct the sample for this analysis, we first limit the core sample to person-years in which an individual files a tax return, claims one or more children, and has income in the EITC-eligible range. We then restrict the sample to individuals who move across 3-digit ZIP codes (ZIP-3s) in some year between 2000 and 2005, to ensure that we have at least four years of data before and after the move. When individuals move more than once, we include only the first move.

Child Birth Sample. Our third research design tracks individuals around the year in which they have a child, which can trigger eligibility for a larger EITC. We observe dates of birth as recorded by the Social Security Administration. As in the movers sample, we restrict attention to births between 2000 and 2005 (to have at least four years of earnings data before and after child birth). We define the parents of the child as all the primary and secondary filers who claim the child as a dependent within 5 years of the child's birth. We then limit the core sample to the set of all such new parents, regardless of whether they file a tax return, yielding a balanced panel. We impute earnings, addresses, and number of children for non-filers using data from the year of child birth or the closest year to the current observation; see the appendix for details.

Descriptive Statistics. We present summary statistics for our cross-sectional analysis sample in Appendix Table 1. Mean total earnings are \$20,091, while mean wage earnings as reported on W-2's are $\$ 18,308$. The mean EITC refund is of $\$ 2,543$. Nearly 70 percent of the tax returns are filed by a professional preparer. The sample consists primarily of young single women with children: only 30 percent are married, and 73 percent of the single filers are female.

19.6 percent of families report non-zero self-employment income in a given year. Our research design requires that EITC knowledge among these self-employed individuals is representative of EITC knowledge among wage earners. Unfortunately, the tax data do not contain information on occupation or industry that would allow us to assess the similarity of self-employed individuals and wage earners in our sample. Data from the Current Population Survey show that the self-employed are more highly represented in less capital-intensive sectors (Hipple 2004). However, most industries and occupations 
have a significant number of self-employed workers, suggesting that there are many conduits for diffusion of knowledge between the two groups.

\section{Neighborhood Variation in Bunching and EITC Knowledge}

In this section, we develop a proxy for local knowledge about the EITC in four steps. First, we document sharp bunching at the first kink of the EITC schedule by self-employed individuals in the aggregate income distribution. Second, we show that the degree of sharp bunching varies significantly across neighborhoods. Third, we show that much of this spatial variation appears to be driven by differences in knowledge about the refund-maximizing kink of the EITC schedule. Finally, we show that individuals in low-bunching areas are unaware not only of the refund-maximizing kink but behave as if the EITC does not affect their marginal tax rates at all income levels. Together, the results in this section establish that self-employed sharp bunching is a proxy for local knowledge that satisfies Assumption 1 above.

\section{A. Aggregate Distributions: Self-Employed vs. Wage Earners}

Figure 1a plots the distribution of total earnings for EITC claimants in 2008 using our cross-sectional analysis sample. The distribution is a histogram with $\$ 1,000$ bins (centered around the first kink of the EITC schedule). We plot separate distributions for EITC filers with one and two or more children, as these individuals face different EITC schedules, as depicted in the figures. Both distributions exhibit sharp bunching at the first kink point of the corresponding EITC schedule, the point that maximizes tax refunds net of other income tax liabilities (such as payroll taxes). This sharp bunching shows that the EITC induces significant changes in reported income, confirming Saez's (2010) findings using public use samples.

Figure $1 \mathrm{~b}$ replicates Figure 1a restricting the sample to wage-earners, defined as taxpayers who report zero self-employment income in a given year. In this figure, there is no sharp bunching at the EITC kinks, implying that all the sharp bunching in Figure 1a is due to the self-employed. However, one cannot determine from Figure $1 \mathrm{~b}$ whether the EITC has an impact on the wage earnings distribution because the impact for wageearners is likely to be much more diffuse because they cannot control their earnings perfectly due to frictions (Chetty et al. 2011).

We identify the diffuse impacts of the EITC on the wage earnings distribution using the research design in Section I. To implement the approach empirically, we interpret sharp bunching among the self-employed as a measure of manipulation in total earnings $\left(\hat{z}_{i}\right.$ in the model) and wage earnings reported on W-2's as true earnings $\left(z_{i}\right)$. Because wage earnings are double reported by employers to the IRS on W-2 forms, individuals have little scope to misreport wage earnings. ${ }^{12}$ In contrast, there is no systematic third-party reporting of self-employment income. Random audits from IRS compliance studies find that more than 80 percent of small informal businesses misreport income. In contrast,

\footnotetext{
${ }^{12}$ Misreporting wage earnings requires collusion between employers and employees. We verify that our results hold in the subgroup of workers at firms with more than 100 employees, where such collusion is unlikely.
} 
compliance rates for wage earnings exceed 98 percent (Internal Revenue Service 1996, Table 3). Consistent with these results, tabulations using audit data from the $2001 \mathrm{Na}$ tional Research Program show that the majority of the sharp bunching at the first kink of the EITC schedule among the self-employed is due to non-compliance (Chetty et al. 2012). The degree of sharp bunching in the post-audit total earnings distribution is less than half that in Figure 1a. In contrast, misreporting among wage-earners is negligible even around the refund-maximizing region of the schedule.

In the remainder of this section, we focus on total earnings $\left(\hat{z}_{i}\right)$ and analyze variation across neighborhoods in the degree of self-employed sharp bunching at the first kink of the EITC schedule.

\section{B. Spatial Heterogeneity in Sharp Bunching}

We analyze spatial heterogeneity at the level of three-digit ZIP codes, which we refer to as ZIP-3s. ${ }^{13}$ We define the degree of sharp bunching in a ZIP-3 $c$ in year $t$, denoted by $b_{c t}$, as the percentage of EITC claimants with children who report total earnings within $\$ 500$ of the first EITC kink and have non-zero self employment income. Note that this definition incorporates both intensive and extensive margin changes in reporting selfemployment income. Thus, part of the variation in bunching across areas is driven by differences in rates of reporting self-employment income, some of which is endogenous to knowledge about the EITC as we show below. ${ }^{14}$

Figure 2 illustrates the spatial variation in $b_{c t}$ in 2008 across the 899 ZIP-3s in the United States. To construct this figure, we divide the raw individual-level cross sectional data in 2008 into 10 deciles based on $b_{c t}$, so that the deciles are population-weighted rather than ZIP-3 weighted. Higher deciles are represented with darker shades on the map. There is substantial dispersion in self-employed sharp bunching across neighborhoods. For example, bunching rates are below 0.75 percent in most of North and South Dakota, but exceed 4 percent in parts of Texas and Florida. While some of the variation in bunching occurs at a broad regional level - for example, bunching is greater in the South - there is considerable variation even within nearby areas. The Rio Grande Valley in Southern Texas has self-employed sharp bunching of $b_{c t}=6.6$ percent; in contrast, Corpus Christi, TX, which is 150 miles away, has bunching of $b_{c t}=2.5$ percent.

Appendix Figure 3 replicates Figure 2 for earlier years to illustrate variation over time. We divide the observations into deciles after pooling all years of the sample, so that the

\footnotetext{
${ }^{13}$ Standard (5 digit) ZIP codes are typically too small to obtain precise estimates of income distributions. Common measures of broader geographical areas such as counties or MSA's are more cumbersome to construct in the tax data or do not cover all areas. There are 899 ZIP-3s in use in the continental United States, shown by the boundaries in Figure 2. ZIP-3 are typically (but not always) contiguous and are smaller in dense areas. For example, in Boston, the 021 ZIP-3 covers roughly the same area as the metro area's subway system.

${ }^{14}$ We have assessed the robustness of our results to several alternative measures of sharp bunching, including (a) defining the denominator using only self-employed individuals rather than the full population to eliminate variation arising from differences in self-employment rates; (b) defining narrower and wider bands than $\$ 500$ around the kink; and (c) calculating excess mass relative to a smooth polynomial fit as in Chetty et al. (2011), which provides a measure of sharp bunching relative to the local density of the income distribution around the first kink. Because self-employed bunching is so sharp (as shown in Figure 1), our results are essentially unchanged with these alternative definitions. As an illustration, we replicate our main results using the definition in (a) in Appendix Figure 2.
} 
decile cut points remain fixed across years. In 1996, shortly after the EITC expanded to its current form, sharp bunching was prevalent in a few areas with a high density of EITC filers (southern Texas, New York City, and Miami). Bunching then spread throughout the country and continues to rise in recent years, consistent with spatial diffusion of knowledge. The mean sharp bunching rate in the U.S. rose from 0.97 percent in 1996 to 2.89 percent in 2009.

Note that there is virtually no sharp bunching in neighborhoods in the ZIP-3-by-year cells that are in the bottom decile of the pooled 1996-2009 sample (see Appendix Figure 4). Hence, these neighborhoods provide a good counterfactual for behavior in the absence of the EITC if the absence of sharp bunching is due to a lack of knowledge about the EITC.

\section{Is the Variation in Bunching Driven by Knowledge?}

We evaluate whether the differences in self-employed sharp bunching across ZIP-3s are driven by differences in knowledge about the refund-maximizing kink of the schedule using two tests. First, we analyze individuals who move across ZIP-3s and test for learning. Second, we correlate bunching rates with proxies for the rate of information diffusion and competing explanatory factors such as local tax compliance rates. ${ }^{15}$

Movers. Our hypothesis that the variation in bunching is driven by differences in knowledge generates two testable predictions about the behavior of movers. The first is learning: individuals who move to a higher bunching area should learn from their neighbors and begin to respond to the EITC themselves. The second is memory: individuals who leave high bunching areas should continue to respond to the EITC even after they move to a lower bunching area. The asymmetric impact of prior and current neighborhoods distinguishes knowledge from other plausible explanations for the spatial variation in bunching. For instance, variation in preferences or tax compliance rates across areas would not directly predict that an individual's previous neighborhood should have an asymmetric impact on current behavior.

We implement these two tests using the movers sample defined in Section II, which includes all individuals in our core sample who move across ZIP-3s at some point between 2000 and 2005. This sample includes 21.9 million unique individuals and 54 million observations spanning 1996-2009. We define the degree of bunching for prior residents as the sharp bunching rate for individuals in the cross-sectional analysis sample living in ZIP-3 $c$ the year before the move. We then divide the ZIP-3-by-year cells into deciles of prior residents' bunching rates by splitting the individual-level observations in the movers sample into ten equal-sized groups.

Figure 3a plots an event study of bunching for movers around the year in which they move. To construct this figure, we define the year of the move as the first year a tax return was filed from the new ZIP-3. We compute event time as the calendar year minus the year of the move, so event year 0 is the first year the individual lives in the new ZIP-3.

\footnotetext{
${ }^{15}$ The most definitive test would be to measure knowledge directly using surveys across different neighborhoods. Collecting more data on knowledge about tax policies across areas would be a very valuable direction for further work in light of the results reported here.
} 
For illustrative purposes, we focus on individuals who live in a ZIP-3 in the fifth decile of the overall bunching distribution in the year prior to the move. We then divide this sample into three groups based on where they move in year 0 - the first, fifth, or tenth bunching decile - and plot sharp bunching rates by event year.

Individuals who move to a neighborhood in the tenth decile start bunching much more after they move. To estimate the magnitude of the impact, we regress an indicator for sharp bunching (i.e., reporting total earnings at the kink and non-zero self employment income) on an indicator for moving to decile 10 , an indicator for event year 0 , and the interaction of the two indicators. We estimate this regression restricting the sample to event years -1 and 0 and deciles 5 and 10 , so that the coefficient on the interaction term $\left(\beta_{10}\right)$ is a difference-in-differences estimate of the impact of moving to decile 10 relative to decile 5. We estimate treatment effects of moving to deciles 1 and 5 using analogous specifications, always using decile 5 as the control group.

Bunching rates rise sharply by $\beta_{10}=1.9$ percentage points for individuals who move to the highest bunching decile, rise by a statistically insignificant $\beta_{5}=0.1$ percentage points for those who stay in a fifth-decile area, and fall slightly (by $\beta_{1}=-0.4$ percentage points) for those who move to the lowest bunching decile. Individuals rapidly adopt local behavior when moving to high bunching areas. The mean difference in self-employed sharp bunching rates for prior residents is 3.6 percentage points between the fifth and tenth deciles. Hence, movers to the top decile adopt 1.9/3.6 $=53$ percent of the difference in prior residents' behavior within the first year of their move.

To distinguish learning and memory more directly, we test for asymmetry in the impacts of increases vs. decreases in sharp bunching rates when individuals move. Figure $3 \mathrm{~b}$ plots changes in mean EITC refunds from the year before the move (year -1) to the year after the move (year 0) vs. the change in local sharp bunching $\Delta b_{c t}$ that an individual experiences when he moves. We bin the x-axis variable $\Delta b_{c t}$ into intervals (of width 0.05 percent) and plot the means of the change in EITC refund within each bin. If the variation in bunching is due to knowledge, there should be a kink in this relationship around 0 : increases in $b_{c t}$ should raise refunds, but reductions in $b_{c t}$ should leave refunds unaffected. We test for the presence of such a kink by fitting separate linear control functions to the points on the left and right of the vertical line, with standard errors clustered by the bins of $\Delta b_{c t}$ (Card and Lee 2007). As predicted, the slope to the right of the kink is significant and positive: a 1 percentage point increase in sharp bunching when $b_{c t} \geq 0$ leads to a $\$ 60$ increase in EITC refunds. In contrast, a 1 percentage point reduction in $b_{c t}$ when $b_{c t} \leq 0$ leads to a statistically insignificant change in EITC refunds of $\$ 6$. The hypothesis that the two slopes are equal is rejected with $p<0.0001$. We find similar asymmetric persistence in wage earnings, implying that individuals learn not just about non-compliance but also about the incentives that affect real work decisions (see Appendix B). ${ }^{16}$

Cross-Sectional Correlations. Table 1 presents a set of OLS regressions of the rate

\footnotetext{
${ }^{16}$ For instance, one may be concerned that norms about tax compliance could have asymmetric persistence: once one observes someone else misreport earnings, it becomes an acceptable habit. The asymmetric persistence of wage earnings rejects such models.
} 
of sharp bunching in each ZIP-3 in 2000 on various correlates. In Column 1, we regress sharp bunching on the local density of EITC filers (defined as the number of EITC claimants with children per square mile), the fraction of individuals who use a tax preparer in each ZIP-3, and ZIP-3 level demographic controls (the percentages of the population foreign born, white, black, Hispanic, Asian, and other race from the 2000 decennial Census). Among a broad range of variables available in the Census, the strongest predictor of sharp bunching is the local density of EITC filers. The predictive power of density - which has an R-squared of 0.6 by itself in a univariate regression - supports the view that the variation in sharp bunching is driven by the diffusion of knowledge through networks. Consistent with learning through networks, we find that the rate of sharp bunching grows more rapidly over time in areas with a high density of EITC filers; see Appendix B for these and other supplementary results. Sharp bunching is also highly correlated with availability of local tax preparers, consistent with prior evidence that professional tax preparers may help disseminate information about the tax code (e.g., Maag 2005, Chetty and Saez 2013).

Next, we evaluate competing explanations for the spatial variation in bunching. Do differences in policies across states explain the variation? Column 2 adds state fixed effects to the specification in Column 1 and shows that density and tax preparation continue to explain a significant portion of the within-state variation in sharp bunching. Consistent with this finding, Column 3 shows that differences in state EITC top-up rates do not have a significant impact on sharp bunching rates. ${ }^{17}$

In Column 4, we analyze whether differences in tax compliance rates $\left(\theta_{c}\right)$ across areas explain the variation in sharp bunching. We implement this analysis using data on random audits from the 2001 National Research Program as follows. First, we define a measure of non-compliance in each state as the fraction of non-EITC claimants who have adjustments of more than $\$ 1000$ in their income due to NRP audits. We define non-compliance rates using individuals who do not receive the EITC to eliminate the mechanical correlation arising from the fact that individuals bunch at the kink primarily by misreporting total earnings. We then regress sharp bunching among EITC claimants in each state on the non-compliance rate, weighting by the number of individuals audited in each state to adjust for differences in sampling weights in the NRP. The correlation between sharp bunching and non-compliance rates is statistically insignificant. In contrast, the density of EITC filers - which we define at the state level in Column 4 so that it is on an equal footing with the compliance measure - continues to strongly predict sharp bunching. ${ }^{18}$ In sum, sharp bunching appears to be more highly correlated with predictors of knowledge diffusion rather than state policies or local norms about tax compliance.

\footnotetext{
${ }^{17}$ Half of the states in the U.S. supplement the Federal EITC by adding between 5 and 40 percent to the federal EITC refund, thus amplifying marginal incentives. WI and MN have top-up rates that vary across demographic groups. In WI, we use the top up rate for individuals with 2 children (14 percent). In MN, we use the mean top up rate as calculated by the Tax Policy Center (33 percent).

${ }^{18}$ State-level tabulations from NRP data were provided by the IRS Office of Research. The NRP sampling frame was not designed to be representative at the state level, so the results here should be interpreted with caution. Unfortunately, compliance data are not available at a finer level of disaggregation than by state. Further analysis of local variation in compliance would be valuable given the substantial amount of within-state variation in bunching.
} 


\section{Perceptions of the EITC Schedule in Low-Bunching Areas}

While the preceding evidence suggests that self-employed sharp bunching provides a proxy for local knowledge about the first kink of the EITC schedule, it does not directly establish that Assumption 1 holds. For instance, individuals who live in low-bunching areas may perceive the EITC to be a flat subsidy at a constant rate or a smoothly varying subsidy without kinks in the schedule. Such misperceptions would generate no bunching at the first kink but would imply that low-bunching areas do not provide a valid counterfactual for behavior in the absence of the EITC. We now present evidence that individuals in low-bunching areas actually appear to have no knowledge about the entire EITC schedule and behave as if $\boldsymbol{\tau}=\mathbf{0}$ on average when they become eligible for the credit.

We assess the tax perceptions of individuals in the lowest-bunching decile by examining changes in the distribution of reported self-employment income around the birth of a first child. As noted above, this event makes families eligible for a much larger EITC refund and sharply changes marginal incentives. We implement this analysis using our child birth sample, which includes approximately 15 million individuals from the core sample who have their first child between 2000 and 2005 . We classify individuals into deciles of sharp bunching based on the level of $b_{c t}$, as measured from the cross-sectional sample, in the ZIP-3 and year in which the child was born.

Figure $4 \mathrm{a}$ plots the distribution of total earnings among self-employed individuals in the year before birth and the year of child birth. The distributions are scaled to integrate to the total fraction of individuals reporting self-employment income in each group, which varies across the groups as shown in Figure 4b below. The reported earnings distribution changes only slightly when individuals in the lowest-bunching decile have a child. In contrast, the distribution of total reported income exhibits substantial concentration at the first kink for individuals in the top-bunching decile. ${ }^{19}$ The fact that the total earnings distribution remains virtually unchanged when individuals have a child in lowbunching areas implies that they perceive no changes in marginal incentives throughout the range of the EITC (rather than simply ignoring the first kink).

Figure $4 \mathrm{~b}$ conducts an analogous test on the extensive margin by plotting the fraction of individuals reporting self employment income by event year around child birth, which is denoted by year 0 . While there are clear trend breaks in the fraction reporting self-employment income around child birth in higher-bunching areas, there is little or no break around child birth in the lowest-bunching decile. Although we have no counterfactual for how self-employment income would have changed around child birth in low-bunching areas absent the EITC, we believe that the costs of manipulating reported self-employment income are unlikely to change sharply around child birth. Hence, Figure $4 \mathrm{~b}$ also supports the view that individuals in low-bunching areas perceive no change in their incentives when they become eligible for the EITC. Provided that individuals

\footnotetext{
${ }^{19}$ To simplify the figure, we only plot the distribution of earnings in the year before the birth for households in lowbunching neighborhoods. The pre-birth distribution in high bunching areas is similar to that in low-bunching areas; in particular, it does not exibit any sharp bunching around the first kink of the EITC schedule.
} 
perceive $\boldsymbol{\tau}=\mathbf{0}$ before they are eligible for the EITC - which is plausible because individuals in the EITC income range who do not have children have little net tax liability it follows that EITC-eligible individuals in the lowest sharp bunching decile behave as if $\boldsymbol{\tau}=\mathbf{0}$, as required by Assumption 1 .

\section{Effects of the EITC on Wage Earnings}

In this section, we identify the impacts of the EITC on the distribution of real wage earnings using self-employed sharp bunching as a proxy for local knowledge about the EITC. We present estimates from two research designs. We first compare W-2 wage earnings distributions across neighborhoods in cross-sections. We then study the impacts of sharp changes in marginal incentives around child birth to obtain our preferred estimates, which rely on weaker identification assumptions.

\section{A. Cross-Neighborhood Comparisons}

As a preliminary test, we compare the distribution of wage earnings in ZIP-3s with low vs. high levels of sharp bunching. Figure 5 plots the distribution of W-2 wage earnings for individuals in the lowest and highest deciles of $b_{c t}$, pooling all years in our cross-sectional analysis sample for which we have W-2 data (1999-2009). We limit the sample to wage-earners with children (individuals who report zero self-employment income). ${ }^{20}$

Panel A considers EITC recipients with one child, while Panel B considers those with two or more children. The vertical lines denote the beginning and end of the refundmaximizing EITC plateau. In both panels, there is an increased concentration of the wage earnings distribution around the refund-maximizing region of the EITC schedule in areas in the top decile of sharp bunching $b_{c t}$. Under Assumption $2 \mathrm{a}-$ which requires that areas with different levels of sharp bunching would have comparable wage earnings distributions in the absence of the EITC - this evidence implies that the EITC induces individuals to choose earnings levels that yield larger EITC refunds in high-knowledge areas. The difference in earnings behavior is quantitatively large and highly statistically significant. For example, average EITC refunds are \$307 (10.7 percent) larger in the top decile relative to the bottom decile for individuals with two or more children.

In the Appendix, we evaluate the robustness of this result by extending the analysis in Figure 5 in three ways. First, we include all neighborhoods and show that the concentration of wage earnings around the plateau rises monotonically with the level of sharp-bunching across all deciles. Second, we show that the pattern remains very similar when we restrict the sample to individuals working at firms with more than 100 employees, making it unlikely that the earnings responses are driven by income misreporting in collusion between firms and workers. Third, we show that wage-earners who move to neighborhoods with higher levels of sharp bunching change their earnings behavior so

\footnotetext{
${ }^{20}$ These restrictions could create selection bias, as reported self-employment income and the number of children claimed are endogenous. We show that both sources of selection bias turn out to be negligible in practice using our child birth research design below.
} 
that their EITC refunds rise, but those who move to lower bunching neighborhoods do not obtain smaller EITC refunds. This asymmetric impact echoes the pattern of learning and memory documented for the self-employed in Figure 3a.

\section{B. Impacts of Child Birth on Wage Earnings}

The simple cross-neighborhood comparisons above could be biased by omitted variables or reverse causality. We now turn to our main research design, which uses individuals without children - who are essentially ineligible for the EITC - as a "control group" to net out any latent differences in earnings behavior across neighborhoods. We implement this strategy by studying changes in earnings around the birth of a first child. The first birth changes low-income families' marginal tax rates significantly and is thus a powerful instrument for tax incentives. The obvious challenge in using child birth as an instrument for tax rates is that it affects labor supply directly. We isolate the impacts of the EITC by again using differences in knowledge about the EITC across neighborhoods. In particular, we compare changes in earnings behavior around child birth for individuals living in areas with high levels of sharp bunching with those living in low-bunching areas. Low-bunching areas provide a counterfactual for how earnings behavior would change around child birth in the absence of the EITC.

We divide our child birth analysis sample into deciles based on sharp bunching in the individual's ZIP-3 in the year of child birth, as described in Section III.D. Figure 6 plots W-2 wage earnings distributions for wage-earners in the year before (Panel a) and the year of first child birth (Panel b). The distributions are reported for those living in deciles 1,5 , and 10 of the sharp bunching distribution when they have a child. In the year before child birth, the wage earnings distributions are virtually identical across areas with low vs. high levels of sharp bunching. ${ }^{21}$ However, an excess mass of wage-earners emerges around the plateau in high bunching areas immediately after birth, showing that individuals in these areas obtain a larger EITC refund. Connecting this result to the cross-sectional correlations in Table 1, Figure 6 suggests that individuals living in areas with a high density of EITC filers have heard more about the credit by the time they have a child and therefore respond more strongly to its incentives.

The identification assumption underlying the research design in Figure 6 is that the direct impacts of child birth on earnings do not vary across neighborhoods with different levels of knowledge about the tax code (Assumption 2b). We assess the validity of this "common trends" assumption by examining trends prior to child birth using an event study design. Let year 0 denote the year in which the child is born (and hence the family becomes eligible for a larger EITC) and define event time relative to this year. Define an individual's simulated EITC credit as the EITC an individual would receive given her wage earnings if she had one child and were single. ${ }^{22}$

\footnotetext{
${ }^{21}$ In Table 1, we showed that areas with higher sharp bunching have a higher density of EITC tax filers. This is not inconsistent with Figure 6a. Figure 6a shows that the conditional earnings distributions among individuals just about to give birth are very similar across areas. However, the unconditional distributions differ across areas (e.g., because of differences in age and number of children). This is why we use an event study around child birth rather than comparisons of earnings distributions across all individuals with and without children for identification.

${ }^{22}$ This simulated EITC credit is a simple statistic for the concentration of the wage earnings distribution around the
} 
Figure 7 plots the simulated EITC by event year for wage earners with incomes in the EITC-eligible range for exactly the same three groups as in Figure 6. For scaling purposes, we normalize the level of each series at the mean simulated credit in $t=-4$ by subtracting the decile-specific mean in $t=-4$ and adding back the mean simulated EITC across the three deciles in $t=-4$ to all observations. Simulated EITC amounts trend similarly in low, middle, and high bunching areas prior to child birth, supporting Assumption 2b. In the year of child birth, the simulated credit jumps significantly in high bunching areas relative to low bunching areas, showing that individuals in high-knowledge areas make an active effort to maintain earnings closer to the refundmaximizing level after having a child. ${ }^{23}$ We estimate the magnitude of the impact using difference-in-differences specifications analogous to those used in the movers event studies in Figure 3a, clustering standard errors at the ZIP-3-by-birth-year level. EITC refunds increase by $\$ 85.4$ (4.5 percent) more from the year before to the year of child birth in the highest bunching decile vs. the lowest bunching decile.

In Figure 8a, we expand the analysis to include all neighborhoods by plotting the change in the simulated EITC from the year before birth (event year -1) to the year of birth (event year 0) vs. the level of sharp bunching $b_{c t_{0}}$ in the individual's ZIP-3 in the year of birth. In this figure, we include all wage earners with incomes in the EITCeligible range, as in Figure 6, as well as those with zero earnings (whose simulated credit is zero) to incorporate extensive-margin responses. Consistent with the preceding evidence, individuals living in areas with higher $b_{c t_{0}}$ (i.e., higher knowledge) have significantly larger increases in simulated EITC amounts around child birth. On average, a one percentage point (0.58 standard deviation) increase in $b_{c t_{0}}$ leads to a $\$ 26.5$ increase in the EITC after child birth. This effect is statistically significant with $p<0.0001$, with standard errors clustered at the ZIP-3-by-birth-year level. Note that the relationship is concave: the marginal impact of living in an area with higher $b_{c t_{0}}$ is greater when $b_{c t_{0}}$ is low. We account for this non-linearity when calculating elasticities and policy impacts below, but report coefficients from linear regressions in this section to provide a simple summary statistic for the average impact.

Endogenous Sample Selection. Our child birth analysis sample makes two restrictions that could potentially lead to selection bias, thereby violating Assumption $2 \mathrm{~b}$. The first restriction is that we can only link parents to children they claim as dependents. Because the decision to claim a child could be endogenous to knowledge about the EITC, this could potentially bias our estimates. Over 97 percent of children are claimed on a tax return within 4 years of their birth (see Appendix A). Hence, endogeneity arising from whether a child is ever claimed is minimal. However, selection bias could arise if the person who claims a child is endogenously selected, e.g. if the family member who gets the highest EITC refund claims the child in high-knowledge areas. Such selection bias should be visible in the period prior to child birth, as it would produce differences in simulated EITC credit amounts in event year -1 in Figures 6a and 7. Stated differently,

EITC plateau. We use the simulated credit with fixed parameters in this analysis rather than the actual credit to separate changes in earnings from mechanical changes in credit amounts when individuals have children.

${ }^{23}$ The slight divergence between the series in year -1 may occur because individuals in high-bunching areas keep their jobs prior to birth, recognizing that they will soon be eligible for a large EITC refund. 
we find sharp changes in earnings behavior within individuals around child birth. Bias can arise only if the decision to claim a child is related to changes in earnings around the time of child birth differentially across areas.

The second restriction we impose is to exclude individuals who report non-zero selfemployment income to isolate wage earnings responses. If the choice to report selfemployment income varies endogenously across areas, this restriction could also bias our estimates of the impact of the EITC on wage earnings. To address this concern, we analyze changes in W-2 earnings around child birth for the full sample, including both wage-earners and the self-employed. We calculate the simulated EITC credit based purely on W-2 wage earnings even if the individual has self-employment income to isolate wage earnings responses. Figure $8 \mathrm{~b}$ shows that the relationship between sharp bunching and the change in EITC amounts around child birth remains highly significant when the self-employed are included, with a point estimate of $\$ 19.4 .^{24}$ We use this technique to adjust for potential endogenous selection by including self-employed individuals and computing EITC amounts based on W-2 earnings in all the remaining tables and figures.

Specification Checks and Additional Tests. In Table 2, we assess the robustness of Figure $8 \mathrm{~b}$ to alternative specifications of the form:

$$
E I T C_{i c t}=\alpha+\beta_{1} b_{c t_{0}}+\beta_{2} \text { post }+\beta_{3} \text { post } \times b_{c t_{0}}+\gamma \mathbf{X}_{i c t}+\varepsilon_{i c t}
$$

We estimate (5) using only observations in the year before and the year of child birth, $t \in\{-1,0\}$. In this equation, $E$ IT $C_{i c t}$ denotes the simulated credit individual $i$ in ZIP-3 $c$ obtains in event year $t$, post denotes an indicator for the year of child birth $(t=0)$, and $\mathbf{X}_{i c t}$ denotes a vector of covariates. The coefficient of interest, $\beta_{3}$, measures the impact of a 1 percentage point increase in sharp bunching $b_{c t_{0}}$ on the change in the simulated credit from the year before to the year after birth. Standard errors are clustered at the ZIP-3-by-birth-year level to account for potential correlation in earnings across residents of an area. Column 1 of Table 2 reports $\beta_{3}$ for the baseline specification in Figure $8 \mathrm{~b}$ (with no controls $\mathbf{X}_{i c t}$ ).

Column 2 replicates Column 1, restricting the sample to individuals working at firms with more than 100 employees (based on the number of W-2's). We continue to find a highly significant impact in this subgroup, implying that these changes are unlikely to be driven solely by reporting effects. Note that this specification excludes individuals with zero earnings from the sample, eliminating extensive-margin responses. The fact that the estimated impact on EITC refunds remains large suggests that the EITC induces significant intensive-margin earnings responses even among those who are already working, a result that we develop further below. ${ }^{25}$

Column 3 adds ZIP-3 fixed effects interacted with the post indicator, so that $\beta_{3}$ is

\footnotetext{
${ }^{24}$ The coefficient is attenuated because we miscalculate EITC amounts for self-employed individuals by using only their wage earnings. We correct for this attenuation bias when computing elasticities below.

${ }^{25}$ This result only provides suggestive evidence of an intensive-margin response because it is based on an endogenously selected sample of individuals who chose to work. We use a decomposition approach below that does not suffer from such selection and confirm that intensive margin responses are significant.
} 
identified purely from variation in $b_{c t_{0}}$ over time within areas. The coefficient on $b_{c t_{0}}$ remains large in this specification, showing that unobservable differences across areas do not drive our findings. This result shows that as knowledge about the EITC - as measured by the degree of sharp bunching - grows over time within an area, the impacts of the program on wage earnings also rise.

In Column 4, we implement a simple placebo test for our child birth research design by replicating the baseline specification for individuals having their third child instead of first child. During the years of child birth that we analyze (2000 to 2005), individuals were eligible for the same EITC credit regardless of whether they had 2 or 3 children. Reassuringly, the relationship between neighborhood sharp bunching and changes in simulated credit amounts (calculated using the one-child EITC schedule) around the birth of the third child is close to zero. This result is confirmed by the series in triangles in Figures $8 \mathrm{a}$ and $8 \mathrm{~b}$, which plot changes in simulated credit amounts from the year before to the year of the birth of a third child.

Phase-In vs. Phase-Out Responses. The welfare consequences of the EITC depend on whether the higher concentration of earnings around the refund-maximizing plateau of the EITC schedule comes from increased earnings for those who would have been in the phase-in region or reduced earnings from those who would have been in the phase-out region. To isolate the phase-in response, we define a "simulated phase-in credit" as the phase-in portion of the EITC schedule (for a single earner with one child) combined with a constant refund above the first kink at the refund-maximizing level. Analogously, we define a "simulated phase-out credit" as the phase-out portion of the schedule combined with a constant refund below the second kink at the refund-maximizing level. Formally, we define the simulated phase-in credit as $\min \left(.34 \times z_{i}, 3050\right)$ and the phase-out credit as $\max \left(3050-.16 \times \max \left(z_{i}-16450,0\right), 0\right)$. The simulated phase-in credit is a convenient summary statistic for earnings increases in the phase-in region because it grows when individuals raise their earnings in the phase-in but is unaffected by changes in earnings in the plateau and phase-out regions. The simulated phase-in credit asks, "How would behavioral responses affect refund amounts if the EITC stayed constant at its maximum level and was never phased out?" The simulated phase-out credit similarly isolates changes in earnings behavior in the phase-out region. We define both simulated credits based purely on wage earnings (but include self-employed individuals in the sample).

Figure 9a plots changes in the simulated phase-in and phase-out credits around child birth vs. the degree of sharp bunching. By construction, the two series plotted in Figure 9a sum to the total change in EITC amounts plotted in Figure 8b. The linear regression coefficients corresponding to these two series are reported in Columns 5 and 6 of Table 2 .

Figure 9a shows that the phase-in response is considerably larger than the phase-out response. We estimate the portion of the earnings response coming from the phasein region non-parametrically as follows. First, based on the analysis in Section III.D, we assume that individuals in bottom-decile neighborhoods have no knowledge about the EITC and can therefore be used as a control group whose behavior is unaffected by EITC eligibility. In Figure 8b, the mean change in simulated EITC refunds in the year 
of child birth in the sample as a whole is $\$ 32.9$, compared with $-\$ 15.4$ for the control neighborhoods in the bottom decile. Hence, the causal impact of EITC eligibility on the simulated refund amount is $\$ 48.3$, an increase of 4.7 percent relative to the prebirth mean of $\$ 1,022$. In Figure 9a, the mean change in the simulated phase-in credit in the full sample is $\$ 29.0$ larger than in the bottom-decile control neighborhoods. It follows that on average, $\$ 29.0 / \$ 48.3=60$ percent of the response to the EITC is driven by increases in earning in the phase-in region. Replicating this calculation for the top decile, we estimate that $\$ 86.9 / \$ 123.9=70$ percent of the earnings response in the highest-knowledge areas comes from the phase-in region, with the remaining 30 percent coming from the phase-out region.

Intensive vs. Extensive Margin Responses. To identify extensive-margin responses, we define "working" as having positive W-2 earnings in a given year. We use the full sample (including non-workers, self-employed individuals, and wage earners) for this analysis. Figure $9 \mathrm{~b}$ plots the change in the fraction of individuals working from the year before to the year of child birth vs. sharp bunching; the corresponding regression coefficient is reported in Column 7 of Table 2. ${ }^{26}$ Consistent with prior studies, we find significant extensive-margin responses. Individuals living in areas with high levels of sharp bunching are more likely to continue working after they have a child than those living in areas with little sharp bunching.

To estimate the relative magnitude of intensive and extensive margin responses, we assume that extensive-margin entrants earn the average EITC refund in the child birth sample conditional on working $(\$ 1,075)$. Under this assumption, the extensive-margin response increases EITC refunds by $\$ 10.8$ on average relative to the bottom decile control neighborhoods. Hence, the extensive margin contributes $\$ 10.8 / \$ 48.3=22$ percent to the increase in EITC refunds. Replicating this calculation under the assumption that extensive-margin entrants earn the maximum EITC refund, we obtain an upper bound on the extensive-margin response of 63 percent. This finding constitutes non-parametric evidence that the EITC induces significant changes in labor supply even among individuals who are already working, confirming the finding in Column 2 of Table 2.

Finally, in Column 8 of Table 2, we analyze the number of W-2's per individual, which is a proxy for the number of distinct jobs an individual held over the year. A one percentage point increase in sharp bunching leads to a 0.017 (0.018 SD) increase in the number of W-2's filed after child birth. Hence, part of the increase in earnings in the phase-in region comes from individuals taking additional part-time jobs. Adjustment in part-time jobs could explain why earnings responses to the EITC are larger in the phasein than the phase-out. In our child birth sample, individuals in the phase-in have 1.59 W-2's per person, at which they earn $\$ 2,400$ per job on average. Those in the phaseout have $1.43 \mathrm{~W}-2$ 's with mean earnings of $\$ 13,700$ per W-2. Because they work more small, part-time jobs, individuals in the phase-in may be able to change their earnings more easily than those in the phase-out. An alternative explanation for larger phase-in

\footnotetext{
${ }^{26}$ The mean fraction of individuals working in this sample is 84 percent in the year before child birth and 86 percent in the year of child birth. The fraction working increases around child birth because this sample includes predominantly young, unmarried women who are entering the labor force and because our definition of "working" is defined as having any earnings over a year. By definition, the newborn child is present only for part of the birth year.
} 
responses is that current perceptions of the EITC focus on phase-in incentives more than the phase-out incentives.

\section{Elasticity Estimates and Policy Impacts}

This section uses the estimates from the child birth design to quantify the impacts of the EITC in two ways. First, we calculate the elasticities implied by the estimated earnings responses. Second, we evaluate the impacts of the EITC on poverty rates.

\section{A. Elasticity Estimates}

One of the main lessons of our study is that the impacts of tax policies cannot be characterized using a single elasticity, as the diffuse behavioral responses we have documented do not conform to the predictions of neoclassical labor supply models. Nevertheless, to benchmark the responses we document to those identified in the prior literature, we calculate the elasticities that would generate the increases in EITC refunds we observe under a neoclassical intensive-margin labor supply model. Importantly, the elasticities reported below should not be interpreted as structural parameters and cannot be used to forecast the impacts of other tax reforms on earnings behavior. Obtaining such elasticity estimates would require estimating a model that incorporates both intensive and extensive margins as well as the frictions that generate diffuse bunching. ${ }^{27}$

Panel A of Table 3 reports elasticity estimates for wage-earners. The first column reports the intensive-margin elasticity that would generate an increase in EITC refunds commensurate to the empirical estimates above. We compute these elasticities as follows. With a standard iso-elastic labor supply function, a frictionless model with elasticity $\varepsilon$ implies

$$
\log (z+\Delta z)-\log (z)=\varepsilon \cdot \log (1-\tau)
$$

where $\tau$ is the actual marginal tax rate an individual faces because of the EITC, $z$ is the level earnings when the EITC marginal tax rate is perceived to be zero, and $z+\Delta z$ is earnings when the EITC marginal tax rate is accurately perceived to be $\tau{ }^{28}$ The change in the EITC refund induced by the earnings response is: $-\tau \cdot \Delta z=-\tau \cdot\left[(1-\tau)^{\varepsilon}-1\right] \cdot z$. Hence, the mean increase in EITC refunds due to behavioral responses in the phase-in and phase-out regions is

$$
\Delta E I T C=-\phi_{1} \tau_{1} \cdot\left[\left(1-\tau_{1}\right)^{\varepsilon}-1\right] \cdot z_{1}-\phi_{2} \tau_{2} \cdot\left[\left(1-\tau_{2}\right)^{\varepsilon}-1\right] \cdot z_{2}
$$

where $\tau_{1}=-34$ percent and $\tau_{2}=16$ percent denote the phase-in and phase-out tax rates, $\phi_{1}=17.8$ percent and $\phi_{2}=23.4$ percent denote the fraction of wage earners with non-zero earnings in the phase-in and phase-out regions in the year after birth in

\footnotetext{
${ }^{27}$ In a frictionless labor supply model, the increase in EITC refunds would come primarily from a point mass in the wage earnings distribution at the kink points of the EITC schedule. A model that produces the diffuse responses we observe empirically would yield different elasticity estimates.

${ }^{28}$ For simplicity, this equation assumes that individuals remain on the interior of the budget segment when they increase earnings by $\Delta z$. Accounting for the kinks in the EITC schedule significantly complicates the calculations and has little impact on the estimated elasticities.
} 
our child birth sample, and $z_{1}=\$ 5,725$ and $z_{2}=\$ 23,217$ denote the mean earnings levels for wage earners in the phase-in and phase-out regions. ${ }^{29}$

We calculate the impact of the EITC on refund amounts $\triangle E I T C$ under our maintained assumption that individuals in the bottom decile of the sharp bunching distribution have no knowledge about the EITC. Recall that in Figure 8b, the mean impact of obtaining EITC eligibility after child birth in the sample as a whole is $\$ 48.3$ larger than in the bottom-decile neighborhoods. 10.8 percent of individuals are self-employed in this sample. As in our model, we assume that these self-employed individuals do not change their real wage earnings, as adjusting self-employment income is less costly. Therefore, the impact of the EITC on the treated (i.e., the wage earners) is $\triangle E I T C=\$ 48.3 /(1-$ $.108)=\$ 54.1$. Substituting this value into (6) and solving for $\varepsilon$ yields $\varepsilon=0.21$ (Table 3 , Column 1, Row 1).

This estimate of $\varepsilon$ assumes that the earnings elasticity is the same in the phase-in and phase-out regions of the schedule. However, as demonstrated in Figure 9a, responses in the phase-in and phase-out regions are quite different in magnitude. We estimate separate phase-in and phase-out region elasticities using the formulas

$$
\begin{aligned}
\Delta \text { Phase-in EITC } & =-\phi_{1} \cdot \tau_{1} \cdot\left[\left(1-\tau_{1}\right)^{\varepsilon_{1}}-1\right] \cdot z_{1} \\
\Delta \text { Phase-out EITC } & =-\phi_{2} \cdot \tau_{2} \cdot\left[\left(1-\tau_{2}\right)^{\varepsilon_{2}}-1\right] \cdot z_{2}
\end{aligned}
$$

We compute the changes in EITC amounts by comparing mean changes in the simulated credits to changes for individuals in the bottom decile in Figure 9a. The resulting estimates, reported in Columns 2 and 3 of Table 3, are a phase-in elasticity of 0.31 and a phase-out elasticity of 0.14 . These estimates confirm that the EITC induces significantly greater earnings increases in the phase-in region than earnings reductions in the phase-out region.

Finally, in Column 4 of Table 3, we report estimates of extensive-margin elasticities. We define the participation tax rate $\tau_{\text {ext }}$ as the mean EITC refund as a percentage of mean income conditional on working. As above, we calculate the impact of the EITC on participation rates as the mean change around child birth minus the change for individuals in bottom-decile neighborhoods in Figure $9 \mathrm{~b}$. We define $\hat{\varepsilon}_{\text {ext }}$ as the log change in participation rates induced by the EITC (starting from the sample mean) divided by the log change in the net-of-participation-tax rate. This yields an estimate of $\hat{\varepsilon}_{\mathrm{ext}}=0.19$. Note that the EITC has smaller effects on average tax rates than marginal tax rates: the participation tax rate changes by 13 percent on average in our sample, whereas the phase-in subsidy rate is nearly three times larger (34 percent). This is why extensive-margin responses account for only 22 percent of the overall increase in EITC refunds even though the intensive and extensive margin elasticity estimates are roughly comparable in magnitude.

\footnotetext{
${ }^{29}$ When calculating $\phi_{1}, \phi_{2}, z_{1}$, and $z_{2}$, we assume that those in the bottom half of the plateau region are in the phase-in and those in the upper half of the plateau are in the phase-out for simplicity. In addition, we restrict attention to individuals with positive earnings because (6) assumes that all behavioral responses come from intensive-margin changes. Since part of the change in EITC refunds $\triangle E I T C$ is due to extensive margin responses, these elasticity calculations should again only be interpreted as the elasticities one would need in a pure intensive margin model to match the observed change in $\triangle E I T C$.
} 
The preceding elasticities apply to the country as a whole given the average level of knowledge about the EITC schedule between 2000 and 2005. In row 2 of Table 3, we report elasticities for areas in the top decile of sharp bunching $b_{c t}$, i.e. the areas with the highest levels of knowledge in our sample. We calculate these elasticities using the same method as above, but define the increase in EITC refunds as the change in EITC refund amounts in the top decile relative to the bottom decile in the year of child birth. The elasticities are roughly 2-3 times larger in areas in the top bunching decile relative to the country as whole.

Panel B of Table 3 replicates Panel A including self-employment income. It reports total earnings elasticities, calculated as in Panel A but using total earnings instead of wage earnings. Total earnings elasticities are much larger because self-employed individuals exhibit large responses to the EITC, especially in high bunching areas. The mean earnings elasticity is 0.36 in the U.S. as a whole and 1.06 in the top bunching decile. Even though less than a fifth of EITC claimants are self-employed, they account for a substantial fraction of the increase in EITC refunds via behavioral responses. As discussed above, most of the self-employed response is driven by non-compliance. Reducing non-compliance responses by auditing or more stringent reporting requirements for self-employment income could make the EITC more effective at raising real earnings.

\section{B. Impacts on the Income Distribution}

We measure the impact of the EITC on the earnings distribution by calculating the fraction of wage-earners in our cross-sectional analysis sample below various fractions of the official poverty line (corresponding to the individual's marital status and number of children). Let $F(\bar{z})$ be the fraction of individuals below threshold $\bar{z}$. We estimate the causal impact of the EITC on $F(\bar{z})$ using our child birth design. Let $t=-1,0$ denote the years before and of child birth. Let $b_{d}=1$ denote ZIP-3-by-birth-year cells in the first decile of the bunching distribution, the no-knowledge control group. The EITC treatment effect is given by the difference-in-differences estimator:

$$
\Delta F(\bar{z})=[F(\bar{z}, t=0)-F(\bar{z}, t=-1)]-\left[F\left(\bar{z}, t=0 \mid b_{d}=1\right)-F\left(\bar{z}, t=-1 \mid b_{d}=1\right)\right]
$$

The first difference is the change in the fraction of individuals below $\bar{z}$ in the full population; the second is the same difference within neighborhoods in the lowest bunching decile. We estimate the fraction who would have been below $\bar{z}$ absent the EITC in the full population as $F(\bar{z})-\Delta F(\bar{z})$.

We characterize the impact of the EITC on the average earnings distribution in 20005 , the period over which we estimate the treatment effect $\Delta F(\bar{z})$ using our child birth sample. The first row of Table 4 shows our estimate of $F(\bar{z})$ without the EITC for various multiples of the poverty line. For instance, we estimate that 31.3 percent of wage-earners in our cross-sectional analysis sample - which consists of EITC-eligible households with children - would be below the poverty line without the EITC. In the second row, we add in EITC payments based on the individual's wage earnings, marital status, and number of dependents. We assume that all eligible households claim their 
benefit and hold wage earnings for each household fixed at the same level as in the first row. The difference between the first and second rows thus reflects the mechanical effect of EITC payments on post-tax incomes. EITC payments shift the income distribution upward significantly; the fraction below the poverty line falls to 21.4 percent. As 15 percent of all US households with children are EITC eligible, the EITC reduces overall poverty rates in the population by approximately 1.5 percentage points. The third row reports statistics for the observed post-EITC income distribution in the aggregate economy. This row incorporates behavioral responses to the EITC on top of the mechanical effects in the second row. Behavioral responses to the EITC further increase incomes at the lowest levels, as workers respond to the marginal subsidy on the phase-in. Taking behavioral responses into account, the fraction below the poverty line with the EITC is 21.0 percent.

In the last row of Table 4, we consider the effect of increasing knowledge of the EITC everywhere to the level observed in the highest bunching decile. This row asks, "How would the EITC affect the US earnings distribution if knowledge about the schedule were at the level in the highest bunching decile?" We estimate this effect by recalculating (7), replacing the first term with the CDFs in the top bunching decile instead of the full sample. We then add this causal effect back to the counterfactual distribution calculated in the first row of Table 4 and recompute EITC refund amounts. The increased knowledge would further lower the fraction below the poverty line to 20.2 percent.

Table 4 yields three main lessons. First, the impacts of the EITC on inequality come primarily through its mechanical effects. Second, behavioral responses tend to reinforce the mechanical effects of the EITC in raising incomes of the lowest earning households. For instance, the fraction earning less than half the poverty line - which is near the end of the phase-in region - falls from 13.2 percent to 8.9 percent due to the mechanical transfer and falls further to 8.2 percent because individuals in the phase-in raise their earnings. In contrast, behavioral responses to the disincentive effects of the EITC in the phase-out region of the schedule have smaller impacts: the fraction earning less than 200 percent of the poverty line falls from 77.1 percent to 70.8 percent due to the mechanical effect, but rises to only 71.3 percent when incorporating behavioral responses. Third, the aggregate response to the EITC still comes from a subset of neighborhoods where behavioral responses are quite large. As knowledge about the EITC's structure continues to spread, the program's impacts on the aggregate wage earnings distribution are likely to grow.

\section{Conclusion}

Research on the impacts of tax policies has confronted two important empirical challenges. First, because federal tax policies often do not vary cross-sectionally, it is difficult to find counterfactuals to estimate causal effects. Second, many individuals respond slowly to tax changes because of inattention and other frictions. This makes it difficult to identify steady-state impacts from short-run changes in behavior around tax reforms. This paper has developed a method of addressing these challenges by using variation in knowledge about the policy to obtain counterfactuals. 
We apply this method to characterize the impacts of the EITC on earnings behavior by using the degree of sharp bunching at the refund-maximizing income level by the self-employed as a proxy for local knowledge about the EITC schedule. We find that the EITC has significant impacts on wage earnings decisions, especially in areas with a high density of EITC claimants, where knowledge about the EITC schedule is more widespread. The fact that earnings responses to the EITC remain concentrated within a small set of neighborhoods more than 10 years after it was expanded to its current form shows that the impacts of tax policy depend heavily on factors omitted from neoclassical models. The earnings responses we document come primarily from intensive-margin increases in labor supply by individuals in the phase-in region. As a result, behavioral responses to the EITC reinforce its direct impacts in raising the incomes of low-income families with children.

Our analysis can be extended and generalized in several dimensions. Most directly, one could use the counterfactuals developed here to study the impacts of the EITC on other behaviors, such as family formation or earnings dynamics. One could also use a similar approach to develop proxies for knowledge about other policies. For instance, several studies have documented sharp bunching around the kinks of the Social Security earnings test schedule (e.g., Friedberg 2000, Haider and Loughran 2008). Using spatial variation in such bunching, one may be able to characterize the impacts of Social Security incentives on retirement behavior. More generally, using low-knowledge groups as counterfactuals could help uncover the impacts of many policies whose effects have proven difficult to characterize with traditional research designs.

\section{References}

Andreoni, James, Brian Erard, and Jonathan Feinstein. 1998. "Tax Compliance." Journal Economic Literature, 36(2): 818-860.

Bollinger, Christopher, Luis Gonzalez, and James P. Ziliak. 2009. "Welfare Reform and the Level and Composition of Income." In Welfare Reform and its Long-Term Consequences for America's Poor. Ed. James P. Ziliak, 59-103. Cambridge, UK: Cambridge University Press.

Card, David and David Lee. 2007. "Regression Discontinuity Inference with Specification Error." Journal of Econometrics, 142(2): 655-674.

Chetty, Raj. 2012. "Bounds on Elasticities with Optimization Frictions: A Synthesis of Micro and Macro Evidence on Labor Supply." Econometrica, 80(3): 969-1018.

Chetty, Raj, John N. Friedman, Tore Olsen, and Luigi Pistaferri. 2011. “Adjustment Costs, Firm Responses, and Micro vs. Macro Labor Supply Elasticities: Evidence from Danish Tax Records." Quarterly Journal of Economics, 126(2): 749-804.

Chetty, Raj, John N. Friedman, and Emmanuel Saez. 2012. "Using Differences in Knowledge Across Neighborhoods to Uncover the Impacts of the EITC on Earnings." National Bureau of Economic Research Working Paper No. 18232.

Chetty, Raj, John N. Friedman, Peter Ganong, Kara E. Leibel, Alan H. Plumley, and Emmanuel Saez. 2012. "Taxpayer Response to the EITC: Evidence from IRS National Research Program,” Tables available at http://obs.rc.fas.harvard.edu/chetty/eitc_nrp_tabs.pdf 
Chetty, Raj and Emmanuel Saez. 2013. "Teaching the Tax Code: Earnings Responses to an Experiment with EITC Recipients." American Economic Journal: Applied Economics, 5(1): 1-31.

Cilke, James. 1998. “A Profile of Non-Filers.” U.S. Department of the Treasury, Office of Tax Analysis Working Paper No. 78.

Eissa, Nada and Hilary Hoynes. 2006. "Behavioral Responses to Taxes: Lessons from the EITC and Labor Supply." In Tax Policy and the Economy. Vol. 20, ed. James Poterba, 74-110. Cambridge: MIT Press.

Eissa, Nada and Jeffrey Liebman. 1996. "Labor Supply Response to the Earned Income Tax Credit." Quarterly Journal of Economics, 111(2): 605-637.

Friedberg, Leora. 2000. "The Labor Supply Effects of the Social Security Earnings Test." Review of Economics and Statistics, 82(1): 48-63.

Gelber, Alexander, and Joshua W. Mitchell. 2012. "Taxes and Time Allocation: Evidence from Single Women and Men." Review of Economic Studies, 79: 863-897.

Grogger, Jeffrey. 2003. "The Effects of Time Limits, the EITC, and Other Policy Changes on Welfare Use, Work, and Income Among Female-Headed Families." Review of Economics and Statistics, 85(2): 394-408.

Haider, Steven J. and David Loughran. 2008. "The Effect of the Social Security Earnings Test on Male Labor Supply: New Evidence from Survey and Administrative Data." Journal of Human Resources, 43(1): 57-87.

Hausman, Jerry A. 1981. "Labor Supply." In How Taxes Affect Economic Behavior. Ed. Henry Aaron and Joseph Pechman. Washington, D.C.: Brookings Institute.

Hipple, Steven. 2004. "Self-employment in the United States: An Update." Monthly Labor Review, July: 13-23.

Hotz, V. Joseph and John Karl Scholz. 2003. "The Earned Income Tax Credit." In Means-Tested Transfer Programs in the United States. Ed. Robert Moffitt. Chicago: Univ. of Chicago Press.

Hotz, V. Joseph and John Karl Scholz. 2006. "Examining the Effect of the Earned Income Tax Credit on the Labor Market Participation of Families on Welfare." National Bureau of Economic Research Working Paper 11968.

Internal Revenue Service. 1996. Federal Tax Compliance Research: Individual Income Tax Gap Estimates for 1985, 1988, and 1992, Publication 1415 (Rev. 4-96). Washington, D.C.: Government Printing Press.

Internal Revenue Service. 2011. Earned Income Credit (EIC), 2009 Publication 596. Washington, D.C.: Government Printing Press.

Internal Revenue Service. 2012. Statistics of Income: Individual Income Tax Returns, 2010 Publication 1304. Washington, D.C.: Government Printing Press.

Kleven, Henrik and Mazhar Waseem. 2012. "Using Notches to Uncover Optimization Frictions and Structural Elasticities: Theory and Evidence from Pakistan." Quarterly Journal of Economics, forthcoming.

Liebman, Jeffrey. 1998. "The Impact of the Earned Income Tax Credit on Incentives and the Income Distribution." In Tax Policy and the Economy. Vol. 12, ed. James Poterba, 83-123. Cambridge: MIT Press. 
Maag, Elaine. 2005. "Paying the Price? Low-Income Parents and the Use of Paid Tax Preparers." New Federalism: National Survey of America's Families B-64, Urban Institute.

Meyer, Bruce. 2010. "The Effects of the Earned Income Tax Credit and Recent Reforms." In Tax Policy and the Economy. Vol. 24(1), ed. Jeffrey Brown, 153-180. Cambridge: MIT Press.

Meyer, Bruce and Dan Rosenbaum. 1999. "Welfare, the Earned Income Tax Credit, and the Labor Supply of Single Mothers." National Bureau of Economic Research Working Paper 7363.

Meyer, Bruce and Dan Rosenbaum. 2001. "Welfare, the Earned Income Tax Credit, and the Labor Supply of Single Mothers." Quarterly Journal of Economics, 116(3): 1063-1114.

Piketty, Thomas and Emmanuel Saez. 2012. “Optimal Labor Income Taxation”, National Bureau of Economic Research Working Paper 18521.

Romich, Jennifer L. and Thomas S. Weisner. 2002. "How Families View and Use the Earned Income Tax Credit: Advance Payment Versus Lump-Sum Delivery." In Making Work Pay. Ed. Bruce Meyer and Douglas Holtz-Eakin. New York: Russell Sage Foundation.

Ross Phillips, Katherin. 2001. "Who Knows About the Earned Income Tax Credit?" Urban Institute Policy Brief No. B-27, January.

Rothstein, Jesse. 2010. "Is the EITC as Good as an NIT? Conditional Cash Transfers and Tax Incidence." American Economic Journal: Economic Policy, 2(1): 177-208.

Saez, Emmanuel. 2010. "Do Taxpayers Bunch at Kink Points?" American Economic Journal: Economic Policy, 2(3): 180-212.

Smeeding, Timothy M., Katherin Ross Phillips, and Michael A. O’Connor. 2002. "The Earned Income Tax Credit: Expectation, Knowledge, Use, and Economic and Social Mobility.” National Tax Journal, 53(4): 1187-1209. 
TABLE 1

Cross-Sectional Correlates of Sharp Bunching

\section{Dependent Variable: Self-Employed Sharp Bunching Rate in ZIP-3 (percent)}

\begin{tabular}{|c|c|c|c|c|}
\hline & (1) & (2) & (3) & (4) \\
\hline $\begin{array}{l}\text { EITC Filer Density } \\
\text { in ZIP-3 }\end{array}$ & $\begin{array}{l}1.86 \\
(0.05)\end{array}$ & $\begin{array}{l}1.94 \\
(0.06)\end{array}$ & $\begin{array}{l}1.92 \\
(0.22)\end{array}$ & \\
\hline $\begin{array}{l}\text { Tax Professional Usage } \\
\text { in ZIP-3 }\end{array}$ & $\begin{array}{l}1.80 \\
(0.26)\end{array}$ & $\begin{array}{l}0.77 \\
(0.31)\end{array}$ & $\begin{array}{c}1.76 \\
(0.39)\end{array}$ & \\
\hline State EITC Top-Up Rate & & & $\begin{array}{l}-0.009 \\
(0.006)\end{array}$ & \\
\hline $\begin{array}{l}\text { EITC Filer Density } \\
\text { in State }\end{array}$ & & & & $\begin{array}{c}1.54 \\
(0.15)\end{array}$ \\
\hline $\begin{array}{l}\text { Tax Professional Usage } \\
\text { in State }\end{array}$ & & & & $\begin{array}{r}0.97 \\
(0.87)\end{array}$ \\
\hline State Non-Compliance Rate & & & & $\begin{array}{l}-1.63 \\
(2.66)\end{array}$ \\
\hline Demographic Controls & $x$ & $x$ & $x$ & $x$ \\
\hline State Fixed Effects & & $x$ & & \\
\hline R-squared & 0.808 & 0.844 & 0.811 & 0.601 \\
\hline Number of ZIP-3s & 870 & 870 & 870 & 870 \\
\hline
\end{tabular}

Notes: Each column reports estimates from an OLS regression run at the ZIP-3 level. Standard errors are reported in parentheses. Standard errors are clustered by state in columns 3 and 4 . The dependent variable in all specifications is sharp bunching in the ZIP-3 in the year 2000. EITC filer density is the number of EITC filers (measured in 1000's) per square mile in the ZIP-3. Tax professional usage is the fraction of EITC filers who use a professional tax preparer in the ZIP-3. State EITC top-up rate is the size of the state EITC top-up as a fraction of the federal EITC; states without a state EITC are coded as zero. State non-compliance rate is the fraction of non-EITC-eligible individuals in a state with a difference between reported and corrected income greater than $\$ 1,000$; this variable is measured using data from the 2001 IRS National Research Program audit data. In column 4, we define EITC filer density and tax professional usage at the state level to put them on an equal footing with the non-compliance variable, which is only available by state even though it may vary more locally. All four specifications include the following ZIP-3 level demographic controls based on data from the 2000 Census: the percentage of the population that is foreign-born, white, black, Hispanic, Asian, and other race. The regressions in columns 1-3 are weighted by the number of individuals in each ZIP-3 in the crosssectional analysis sample; the regression in column 4 is weighted by the product of the NRP sample size and the number of individuals in each ZIP-3. 
TABLE 2

Impacts of EITC on Wage Earnings: Regression Estimates from Child Birth Design

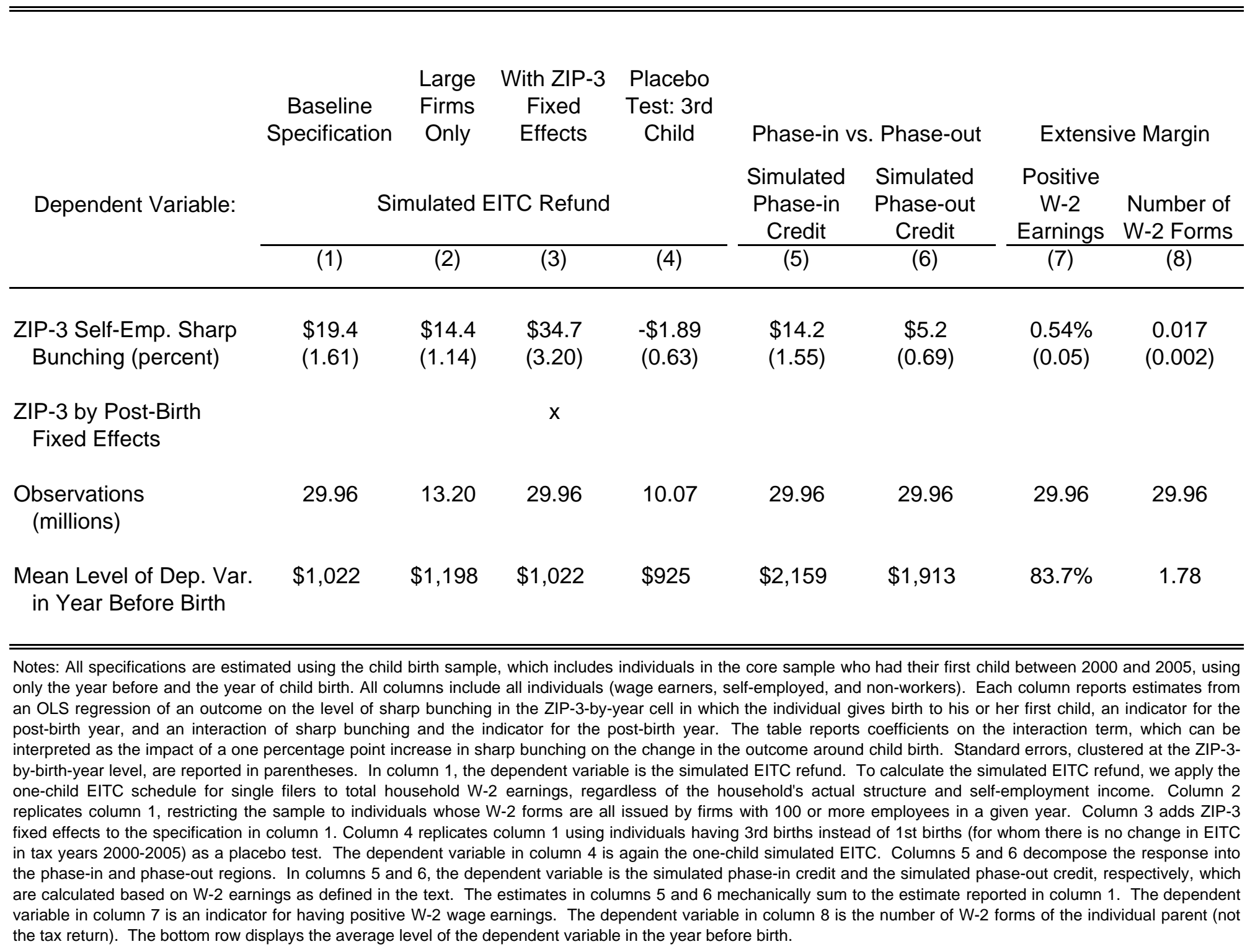


TABLE 3

Elasticity Estimates Based on Change in EITC Refunds Around Birth of First Child

\begin{tabular}{lcccc}
\hline \hline & $\begin{array}{c}\text { Mean } \\
\text { Elasticity }\end{array}$ & $\begin{array}{c}\text { Phase-in } \\
\text { Elasticity }\end{array}$ & $\begin{array}{c}\text { Phase-out } \\
\text { Elasticity }\end{array}$ & $\begin{array}{c}\text { Extensive } \\
\text { Elasticity }\end{array}$ \\
\cline { 2 - 5 } & A. Wage Earnings & $(3)$ & $(4)$ \\
\hline & & & & \\
Elasticity in U.S. 2000-2005 & 0.21 & 0.31 & 0.14 & 0.19 \\
& $(0.012)$ & $(0.018)$ & $(0.015)$ & $(0.019)$ \\
Elasticity in top decile ZIP-3s & 0.55 & 0.84 & 0.29 & 0.60 \\
& $(0.020)$ & $(0.031)$ & $(0.020)$ & $(0.034)$ \\
& & & & \\
Elasticity in U.S. 2000-2005 & T. Total Earnings & & 0.36 \\
& & & & \\
& $(0.36$ & 0.65 & 0.11 & $(0.019)$ \\
Elasticity in top decile ZIP-3s & 1.06 & $(0.030)$ & $(0.006)$ & $(0.040)$ \\
\hline \hline
\end{tabular}

Notes: Columns 1-3 of this table report elasticities required to generate the observed change in EITC refunds due to earnings responses in a frictionless intensive-margin labor supply model. Column 4 reports estimates of participation elasticities, defined as the impact of a 1 percent increase in the average tax rate on the fraction of individuals working. All columns use estimates from the child-birth research design, with neighborhoods in the lowest sharp-bunching decile used as a counterfactual for behavior in the absence of the EITC. The first panel reports elasticities using wage earnings responses; the second panel reports elasticities using total earnings responses (including self-employment income). Standard errors are reported in parentheses. In each panel, the first row reports the mean elasticity implied for the U.S. as a whole, while the second row reports the elasticity in the top bunching decile of ZIP-3-by-year cells. Column 1 reports the intensive margin elasticity required to generate the observed increases in total EITC amounts around child birth. Column 2 reports the elasticity in the phase-in range required to generate the observed increases in simulated phase-in EITC amounts. Column 3 reports the elasticity in the phaseout range required to generate the observed increases in the simulated phase-out EITC amounts. The top decile elasticities are calculated to match the increase in EITC amounts around child birth in decile 10 relative to decile 1; the U.S. elasticities are calculated to match the mean increase in EITC amounts in the sample as a whole relative to decile 1 . Column 4 reports estimates of the log change in employment rates divided by the log change in average tax rates. See the text for additional details on the calculation of these elasticities. 
TABLE 4

Impact of EITC on Wage Earnings Distribution of EITC-Eligible Households

\begin{tabular}{|c|c|c|c|c|}
\hline & \multicolumn{4}{|c|}{ Percent of EITC-Eligible Households Below Threshold } \\
\hline & $(1)$ & $(2)$ & (3) & $(4)$ \\
\hline & $\begin{array}{l}50 \text { Percent of } \\
\text { Poverty Line }\end{array}$ & $\begin{array}{l}100 \text { Percent of } \\
\text { Poverty Line }\end{array}$ & $\begin{array}{l}150 \text { Percent of } \\
\text { Poverty Line }\end{array}$ & $\begin{array}{l}200 \text { Percent of } \\
\text { Poverty Line }\end{array}$ \\
\hline No EITC Counterfactual & $13.15 \%$ & $31.31 \%$ & $53.81 \%$ & $77.06 \%$ \\
\hline $\begin{array}{l}\text { EITC with No Behavioral } \\
\text { Response }\end{array}$ & $8.92 \%$ & $21.37 \%$ & $41.56 \%$ & $70.82 \%$ \\
\hline $\begin{array}{l}\text { EITC with Avg. Behavioral } \\
\text { Response in U.S. }\end{array}$ & $8.16 \%$ & $21.00 \%$ & $41.97 \%$ & $71.29 \%$ \\
\hline $\begin{array}{l}\text { EITC with Top Decile } \\
\text { Behavioral Response }\end{array}$ & $6.73 \%$ & $20.24 \%$ & $42.56 \%$ & $72.08 \%$ \\
\hline
\end{tabular}

Notes: This table presents CDF's of wage earnings distributions under various scenarios. Each column reports the CDF of the income distribution of EITC-eligible wage earners with dependents at various thresholds relative to the Federal Poverty Line (FPL). We calculate the FPL for each observation in our sample based on year, marital status and number of children. The first row shows statistics for the counterfactual wage earnings distribution if there were no EITC. To construct this distribution, we first estimate the causal impact of the EITC on wage earnings using the difference-in-differences estimator around child birth discussed in the text. We then subtract this estimate of the causal impact of the EITC from the CDF of the observed unconditional wage earnings distribution in our sample between 2000-2005. The second row recomputes the CDF in the first row after mechanically adding the EITC payments each household would receive based on its characteristics. The third row reports the observed CDF in our sample using the unconditional post-EITC wage earnings distribution. This row incorporates the effects of both mechanical transfers and behavioral responses to the EITC. The fourth row reports the counterfactual net earnings distribution if the level of information increased in all areas to that of neighborhoods in the highest decile of self-employed sharp bunching in our sample. We estimate this effect by recalculating the difference-in-differences estimate of the causal impact of the EITC using the top bunching decile instead of the full sample. We then add this causal effect back to the counterfactual distribution calculated in the first row and recompute EITC refund amounts. 


\section{FIGURE 1}

\section{Aggregate Earnings Distributions for EITC-Eligible Tax Filers}
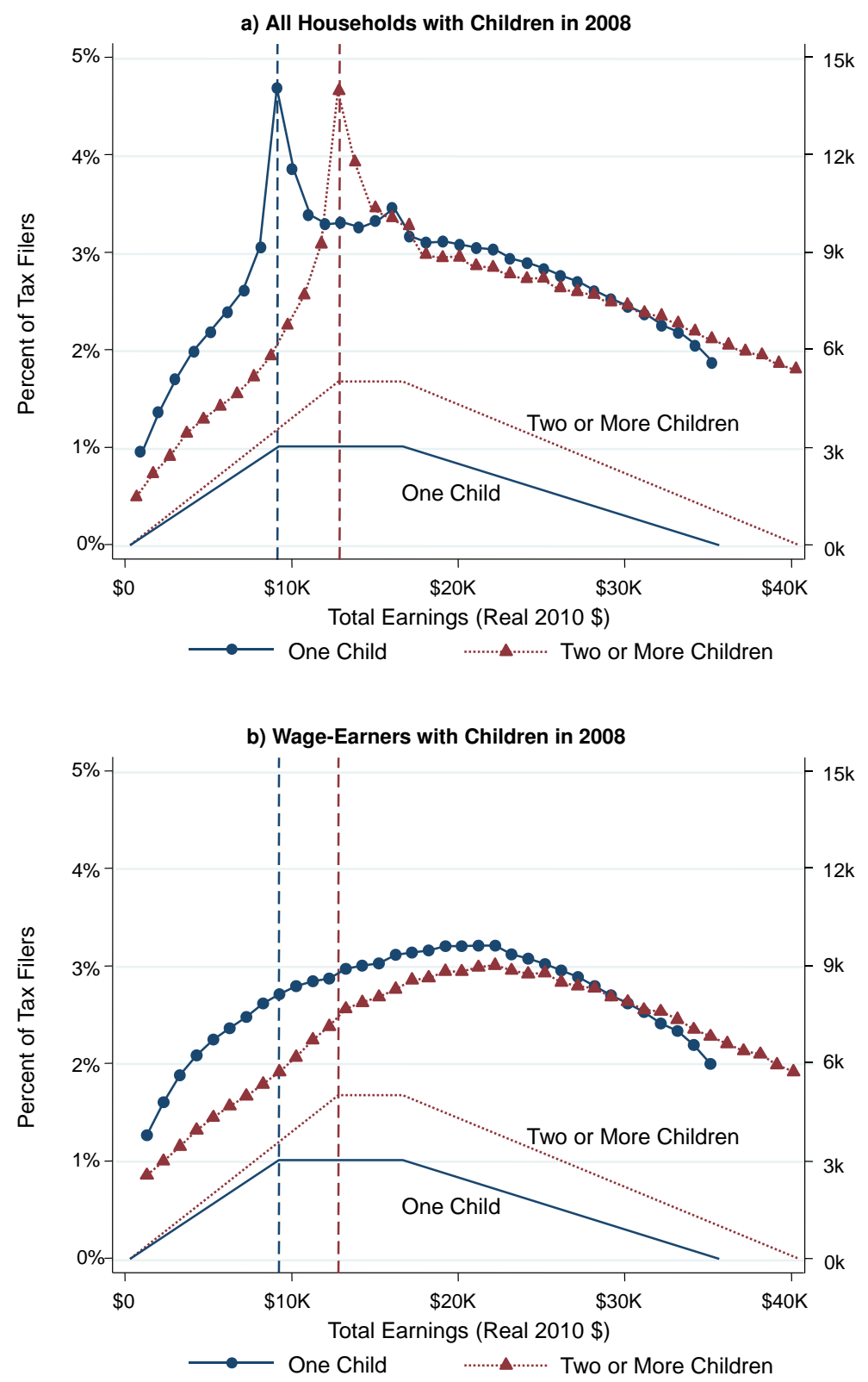

Notes: Panel A plots the distribution of total earnings for all individuals in our cross-sectional analysis sample in 2008, which includes primary tax filers who report one or more children and have income in the EITC-eligible range. This and all subsequent distributions are histograms with $\$ 1,000$ bins centered around the first kink of the EITC schedule. Total earnings is the total amount of earnings used to calculate the EITC and is essentially the sum of wage earnings and self-employment income reported on Form 1040. We plot separate distributions for households claiming one child and households claiming two or more children. Panel B repeats Panel A for wage earners, i.e. households who report no self-employment (Schedule C) income in 2008. Each panel also shows the EITC credit schedule for single filers with one and two or more children in 2008 (right scale). The dashed lines depict the income level that maximizes refunds net of other tax liabilities. Married households filing jointly face schedules with the same first kink point, but a plateau region extended by $\$ 3,000$. In this and all subsequent figures, dollar values are scaled in 2010 real dollars using the IRS inflation adjustment. 


\section{FIGURE 2}

Self-Employed Sharp Bunching Rates Across Neighborhoods

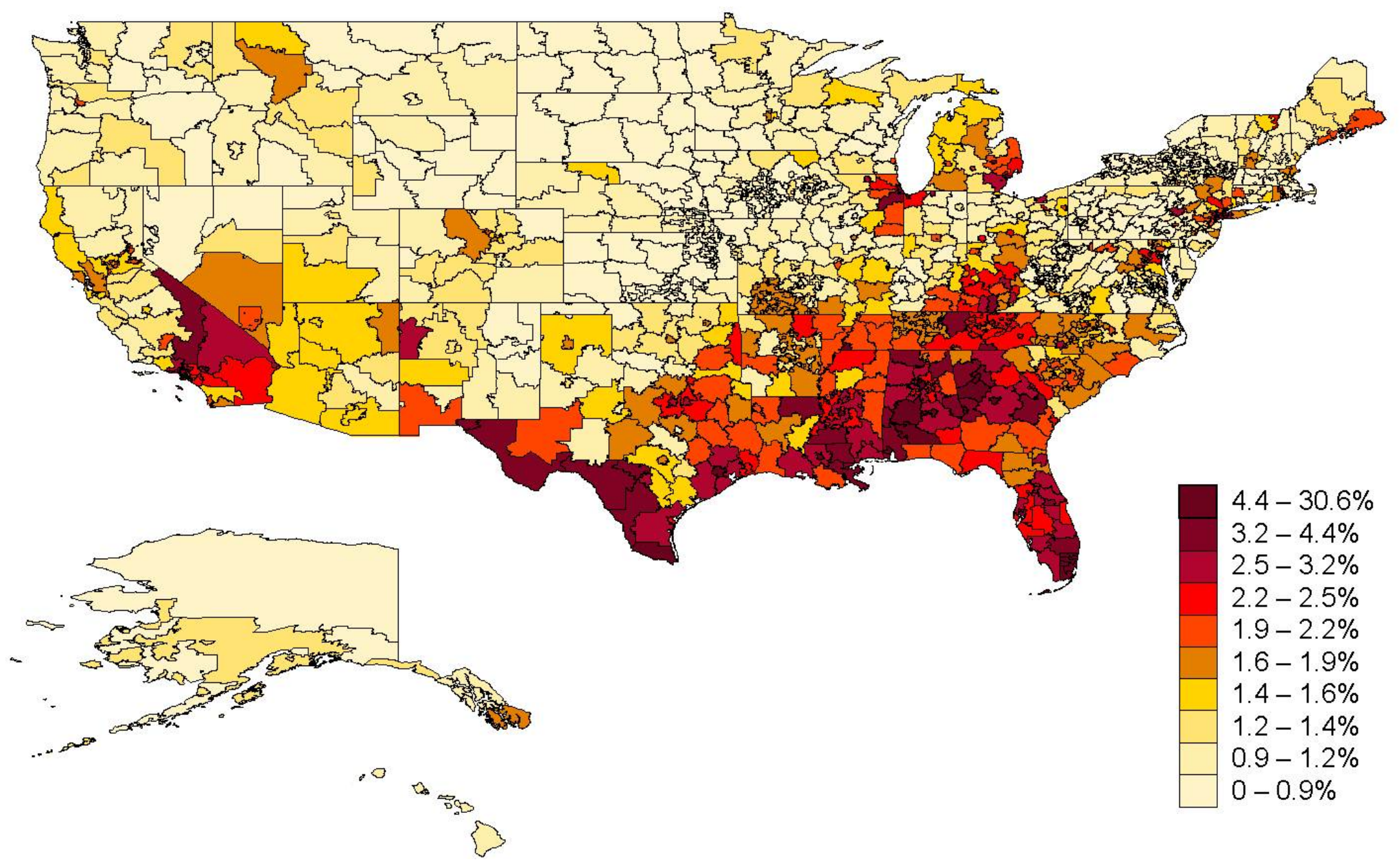

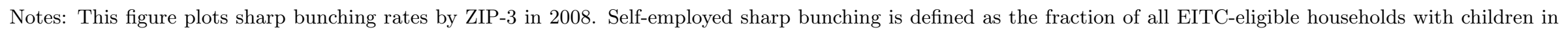

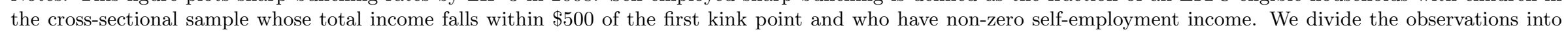
deciles within the 2008 cross-sectional sample. Each decile is assigned a different color on the map, with darker shades representing higher levels of sharp bunching. 


\section{FIGURE 3}

\section{Impact of Moving to Neighborhoods with Lower vs. Higher Sharp Bunching}

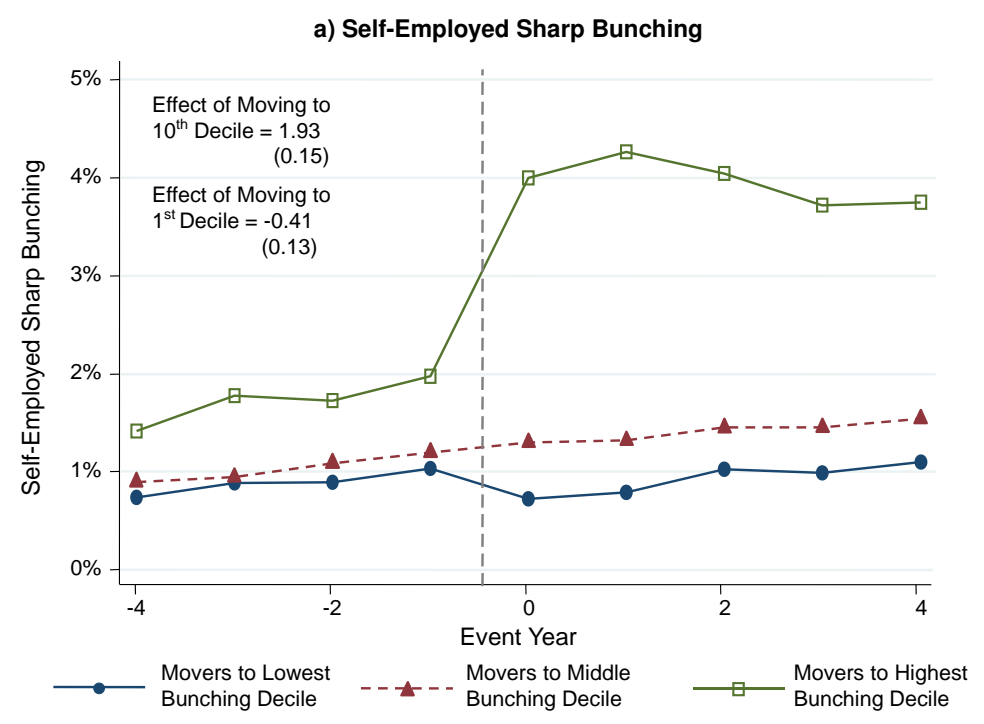

b) EITC Refund Amount

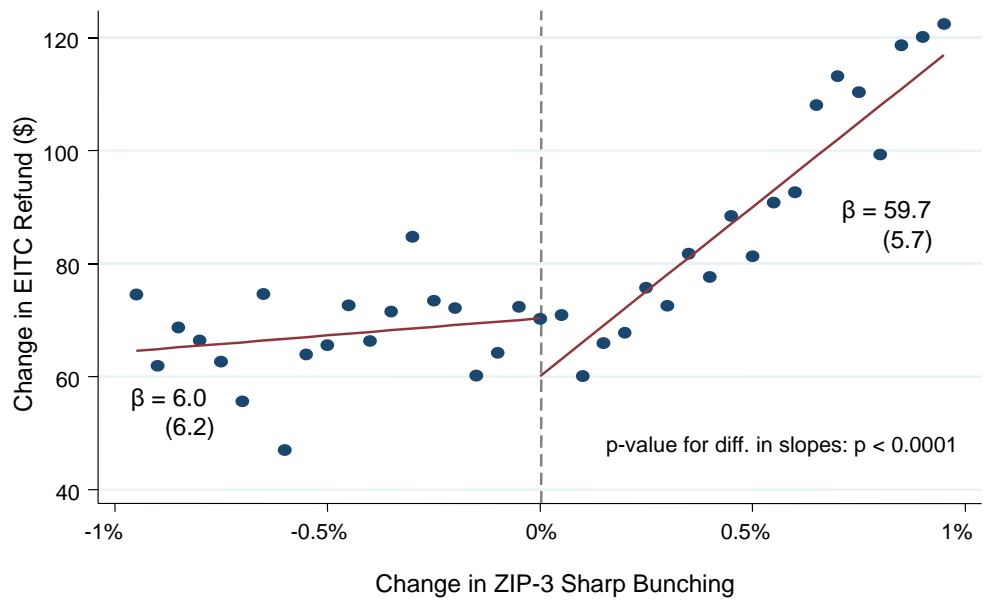

Notes: This figure is drawn using the movers sample, which includes all individuals in our core sample who move across ZIP-3s in any year between 2000 and 2005. If an individual moves more than once, we use only the first move. We define event time as the calendar year minus the year of the move, so year 0 is the year in which the individual moves. To construct the figure, we first define the degree of bunching for prior residents of ZIP-3 $c$ in year $t$ as the sharp bunching rate for individuals in the cross-sectional analysis sample living in ZIP-3 $c$ in year $t-1$. For Panel A, we then divide the ZIP-3-by-year cells into ten deciles of prior residents' bunching rates by splitting the individual-level observations in the movers sample into ten equal-sized groups. Panel A plots an event study of self-employed sharp bunching among individuals who move from ZIP-3-by-year cells in the 5 th decile to cells in the 1 st, 5 th, and 10 th deciles. We include only individual-year observations in which the mover has one or more children and has total earnings in the EITC-eligible range. The coefficients and standard errors are estimated using difference-in-differences regression specifications comparing changes from year -1 to 0 for movers to the 10 th or 1 st deciles with changes for those moving to the 5th decile. See text for details. Standard errors are clustered at the ZIP-3-by-year of move level. Panel B plots changes in EITC refund amounts from the year before the move (event year -1 ) to the year after the move (event year 0) vs. changes in the level of residents' sharp bunching across the old and new ZIP-3s. We define the change in ZIP-3 sharp bunching as the difference between bunching of prior residents of the ZIP-3 where the mover lives before the move and bunching in the ZIP-3 where the mover lives after the move. We group individuals into 0.05 percent-wide bins on changes in sharp bunching and then plot the means of the change in average EITC refund within each bin. The solid lines represent best-fit linear regressions estimated on the microdata separately for observations above and below 0 . The estimated slopes are reported next to each line along with standard errors clustered by bin. 
FIGURE 4

\section{Impacts of Child Birth on Reported Self-Employment Income}
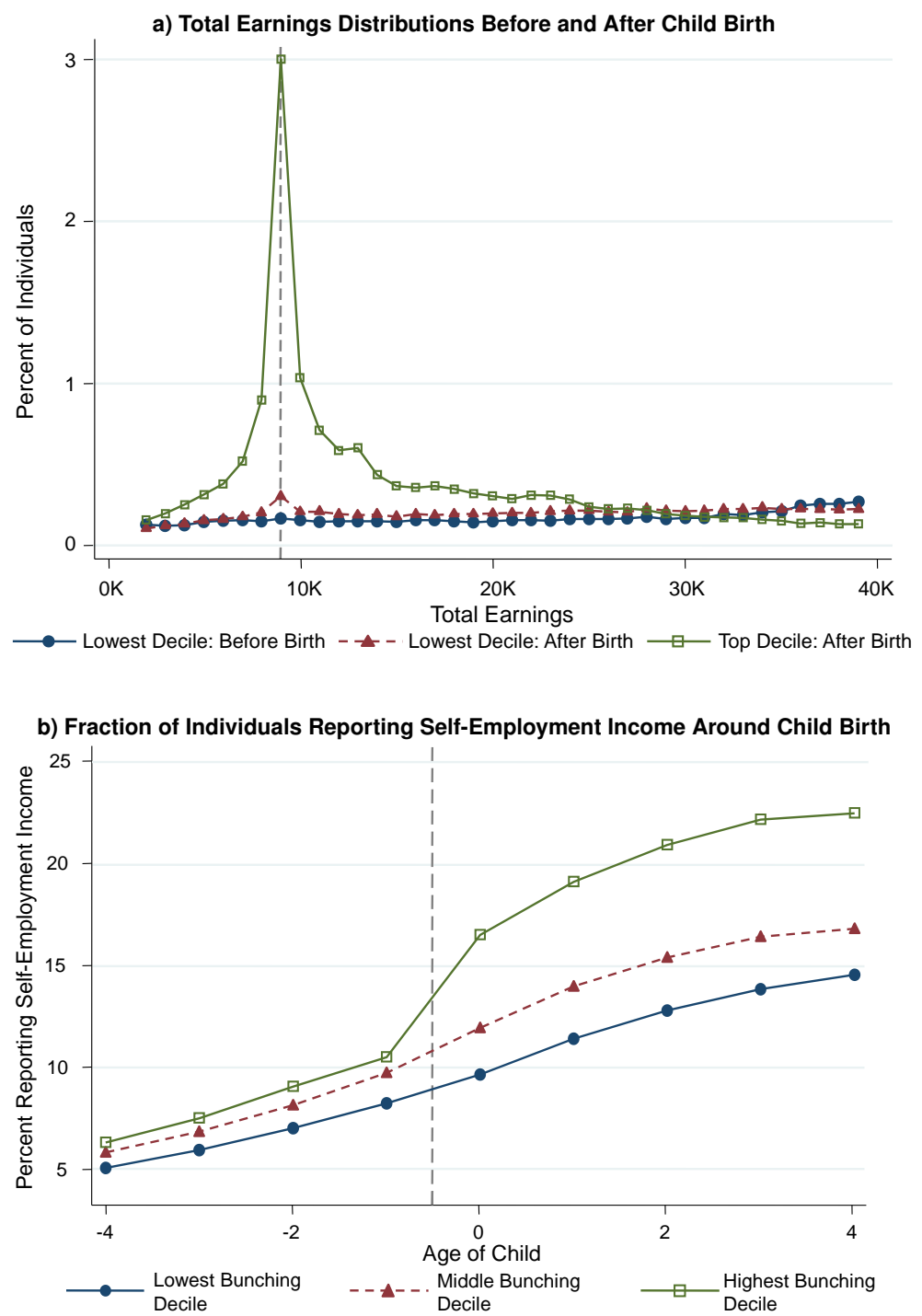

Notes: These figures are drawn using the child birth sample, which includes individuals from the core sample who give birth to their first child between 2000 and 2005. We classify individuals into deciles of sharp bunching based on the level of sharp bunching for residents of the ZIP-3 they inhabit in the year in which they have a child. Panel A includes only individuals with non-zero self employment income and plots the distribution of total earnings in the year before child birth for individuals in the lowest bunching decile, the distribution in the year of child birth for individuals in the lowest bunching decile, and the distribution in the year of child birth for individuals in the highest bunching decile. To simplify the figure, we omit a plot of pre-birth earnings for individuals in the highest bunching decile, since the distribution is similar to that of the lowest bunching decile, and in particular does not exhibit any sharp bunching around the first kink of the EITC schedule. Panel B plots an event study of the fraction of individuals in the child birth sample reporting non-zero self-employment income around child birth for individuals giving birth in 1st, 5th, and 10th decile ZIP-3s. 


\section{FIGURE 5}

\section{Wage Earnings Distributions in Lowest vs. Highest Bunching Deciles}
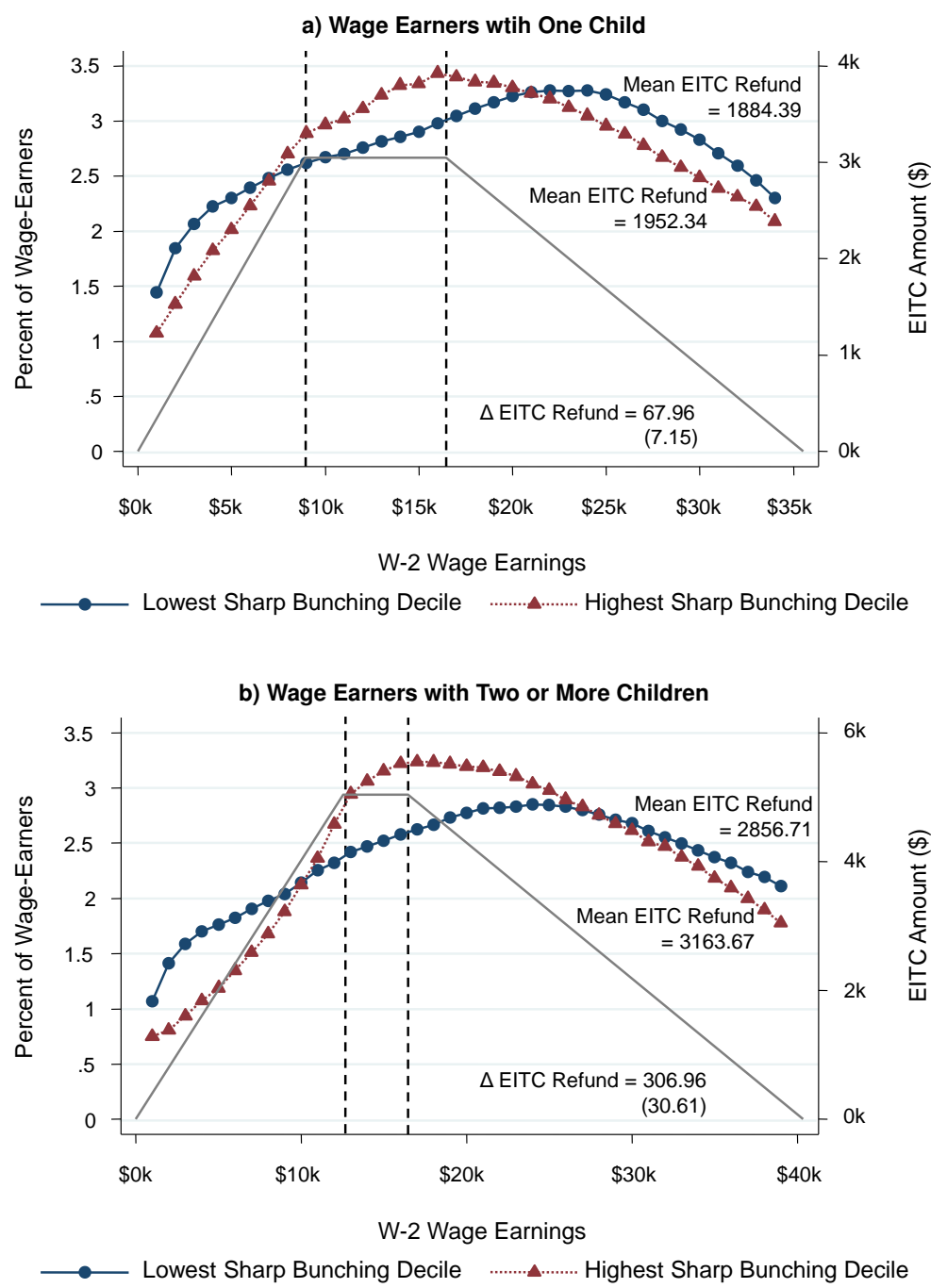

Notes: This figure plots W-2 wage earnings distributions for households without self-employment income using data from the cross-sectional sample from 1999-2009. The series in triangles includes individuals in ZIP-3-by-year cells in the highest self-employed sharp bunching decile, while the series in circles includes individuals in the lowest sharp bunching decile. Selfemployed sharp bunching is defined as the percentage of EITC claimants with children in the ZIP-3-by-year cell who report total earnings within $\$ 500$ of the first EITC kink and have non-zero self-employment income. We divide the observations in the pooled dataset covering 1999-2008 into deciles of sharp bunching, so that the decile cut points remain fixed across years. Panel A plots the distribution for households with one child; panel B plots the distribution for households with two or more children in 1999-2008 and exactly two children in 2009. In each panel we compute the mean EITC refund for individuals in the highest and lowest deciles of sharp bunching, and report the difference between the two groups with standard errors clustered at the ZIP-3-by-birth-year level. The figures also show the relevant EITC schedule for single households in each panel (right scale); the schedule for married households has the same first kink point but has a plateau that is extended by an amount ranging from $\$ 1,000$ in 2002 to $\$ 5,000$ in 2009 . 


\section{FIGURE 6}

\section{Wage Earnings Distributions Before and After Birth of First Child}
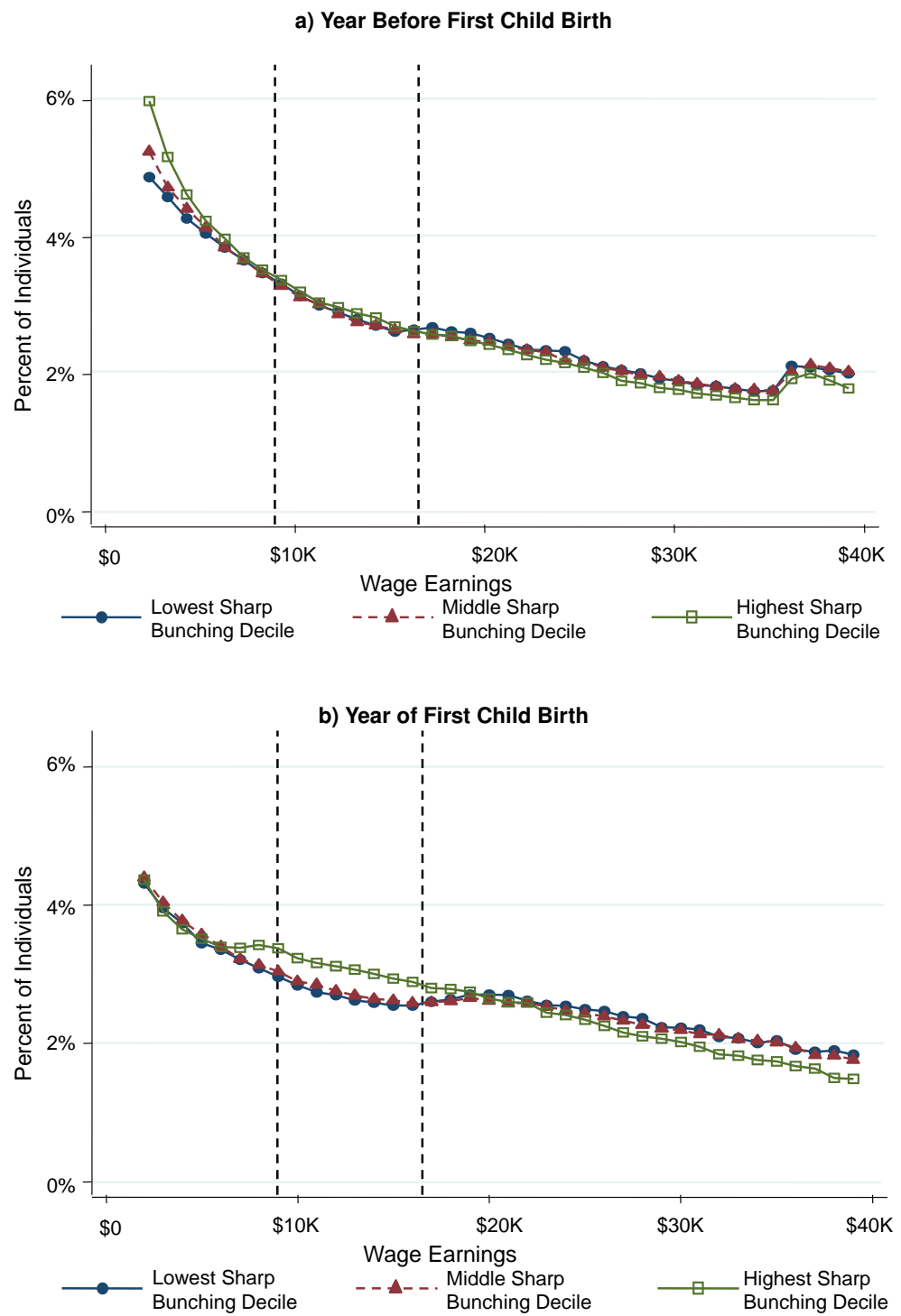

Notes: These figures are drawn using the child birth sample, which includes individuals from the core sample who give birth to their first child between 2000 and 2005. We classify individuals into deciles of sharp bunching based on the level of sharp bunching for residents of the ZIP-3 they inhabit in the year in which they have a child. The figures only include wage-earners (those with no self-employment income) with positive W-2 earnings. Panel A plots W-2 wage earnings distributions in the year before child birth for individuals giving birth in ZIP-3-by-year cells in the 1st, 5th, and 10th deciles. Panel B replicates these distributions for the year of child birth. The dashed lines demarcate the beginning and end of the refund-maximizing plateau region of the EITC schedule for a single individuals with one child. 


\section{FIGURE 7}

\section{Event Study of Simulated EITC Around Birth of First Child}

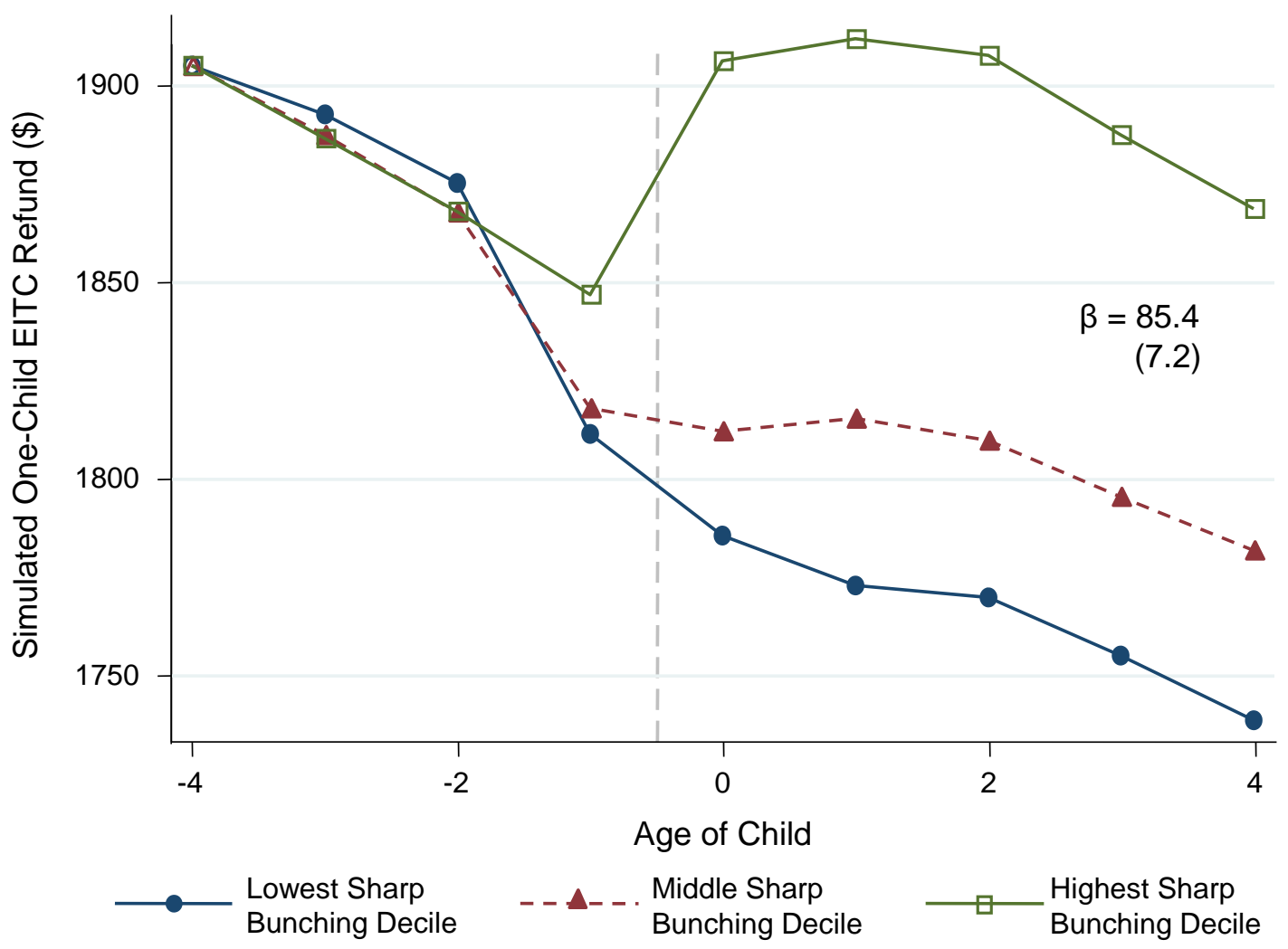

Notes: This figure plots an event study of the simulated EITC refund for wage earners around the year in which they have their first child. To calculate the simulated credit, we apply the one-child EITC schedule for single filers to total household W-2 earnings, regardless of the household's actual structure. The figure plots mean simulated credit amounts by event year for the exactly the same three groups as in Figure 6. For scaling purposes, we normalize the level of each series at the mean simulated credit in $t=-4$; that is, we subtract the decile-specific mean in $t=-4$ and add back the mean simulated EITC across the three deciles in $t=-4$ to all observations. The coefficient compares changes in the simulated credit amount from year -1 to 0 across the highest and lowest bunching deciles, estimated using a difference-in-differences regression specification as in equation (5) in the text. The standard error, reported in parentheses, is clustered at the ZIP-3-by-birth-year level. See the notes to Figure 6 for sample and bunching decile definitions. 
FIGURE 8

\section{Changes in EITC Refund Amounts Around Child Birth vs. Sharp Bunching Rates}

a) Wage Earners Only

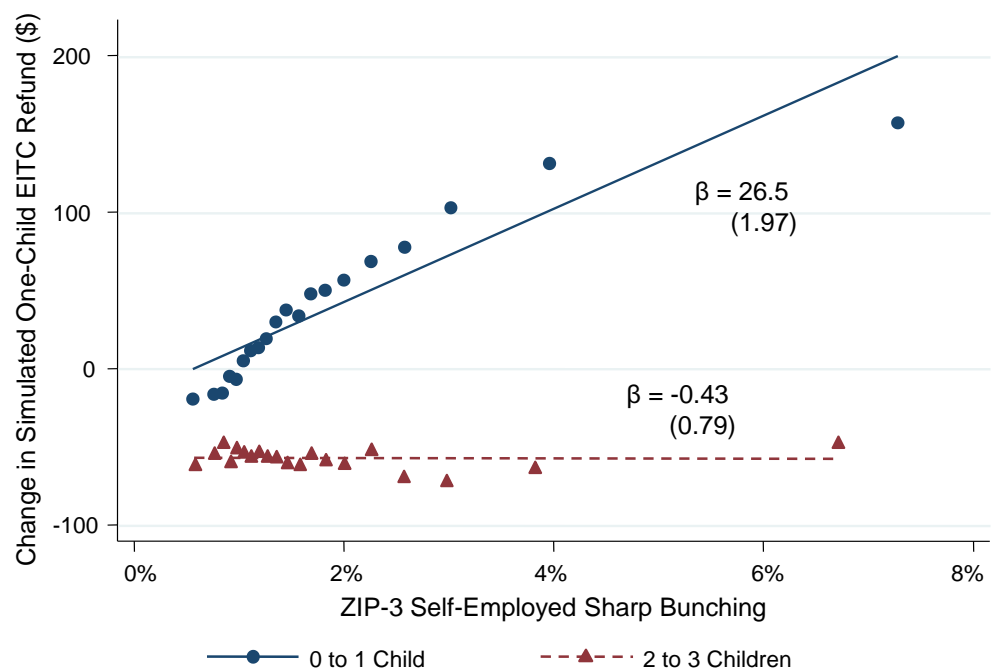

b) Full Sample, with EITC Amounts based on Wage Earnings

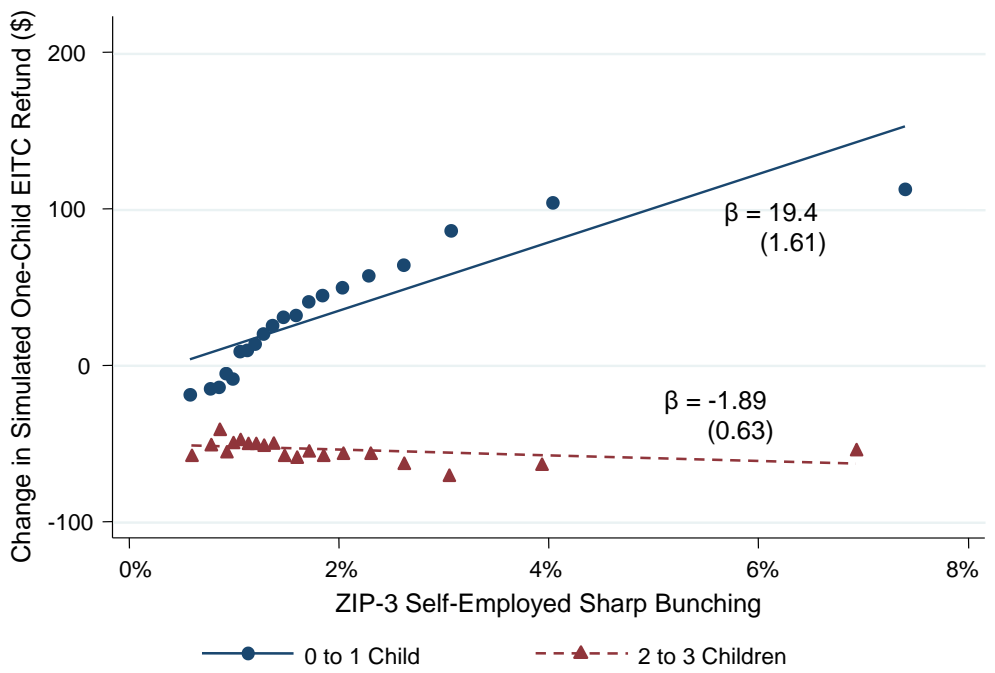

Notes: These figures plot changes in simulated EITC refund from the year before to the year of child birth (year -1 to year 0 in Figure 7) vs. the self-employed sharp bunching rate in the individual's ZIP-3 in the year of birth. Panel A includes only individuals in the child birth sample without self-employment income; Panel B includes all individuals in the child birth sample. In both panels we apply the one-child EITC schedule for single filers to total household W-2 earnings, regardless of the household's actual structure and self-employment income, to calculate the simulated credit. The series in circles plots changes in simulated one-child EITC around the birth of the first child; the series in triangles plots changes in simulated one-child EITC around the birth of the third child. To construct the " 0 to 1 Child" series, we split the observations with first births into twenty equal-sized bins based on the degree of self-employed sharp bunching in the individual's ZIP-3-by-birth-year cell. Within each bin, we then calculate the mean change in simulated EITC from the year before to the year of the birth and plot this mean change against the sharp bunching rate. The "2 to 3 Child" series repeats this procedure for all third births (i.e, where the individual claimed two children the year before), once again using the one-child EITC schedule for single filers to calculate the simulated EITC credit. We estimate the best-fit lines and slopes using an OLS regression of the change in simulated credit on sharp bunching in the individual data, with standard errors clustered at the ZIP-3-by-birth-year level. See the notes to Figure 6 for further details on the child birth sample. 


\section{FIGURE 9}

\section{Phase-In, Phase-Out, and Extensive Margin Responses}

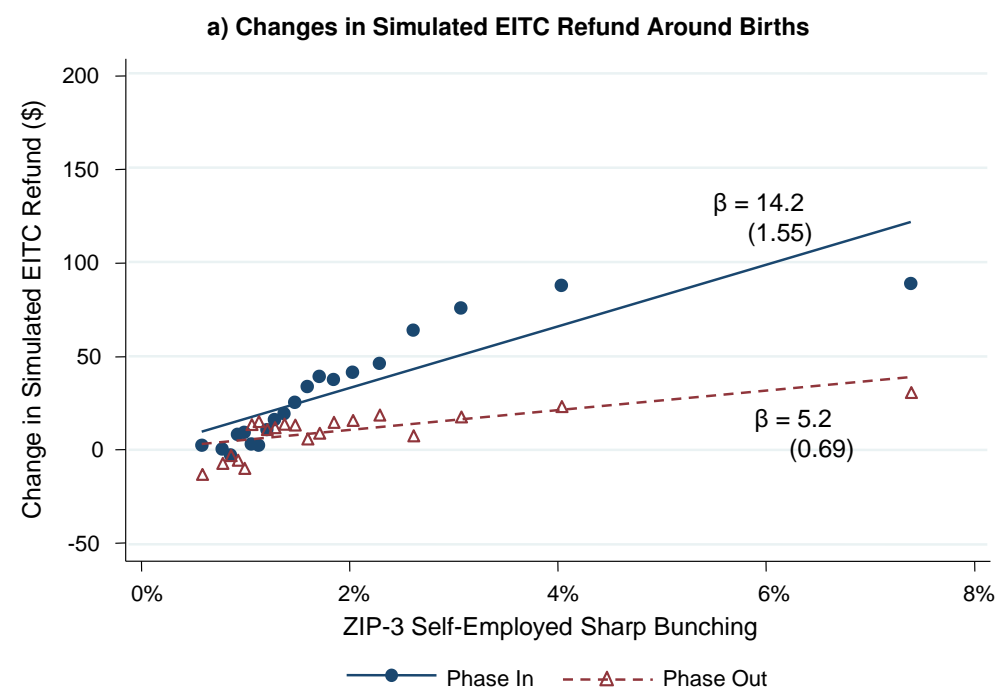

b) Extensive Margin: Changes in Fraction Working around First Birth

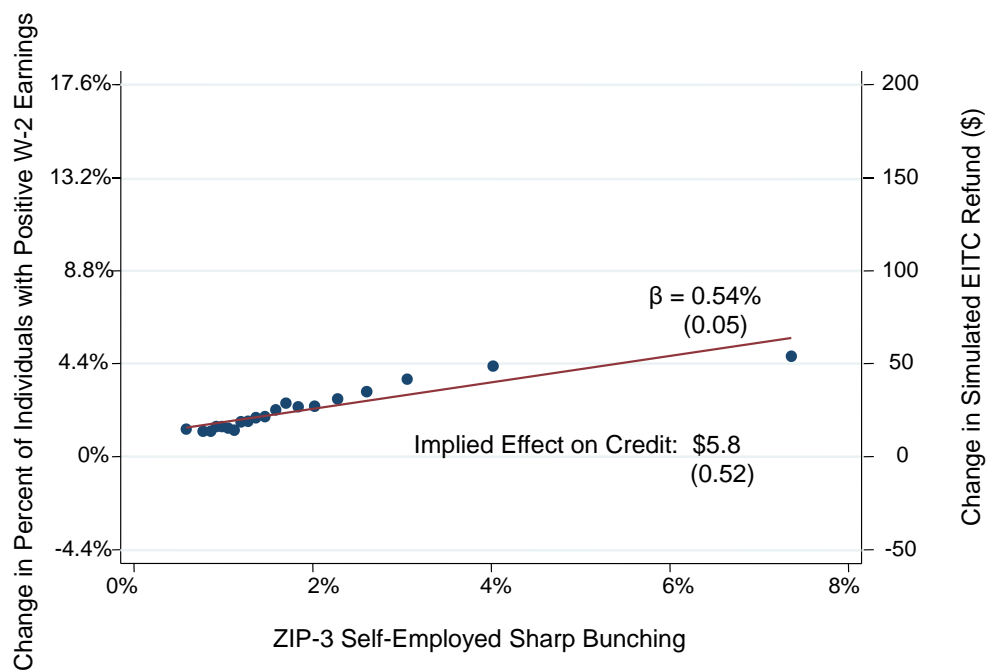

Notes: This figure decomposes the EITC response to the birth of a first child into the phase-in, phase-out and extensive margin responses. To do so, we replicate the "0 to 1 Child" series in Figure 8 b, replacing the simulated EITC variable with other measures. Panel A distinguishes phase-in and phase-out responses. To calculate the phase-in response, we calculate the simulated credit using the simulated phase-in credit defined in the text instead of the actual EITC schedule. For the phase-out response, we use the simulated phase-out credit instead. Panel B replaces the simulated EITC schedule with an indicator for positive W-2 wage earnings. We translate the extensive margin impact to an implied effect on EITC amounts by assuming that new workers earn the average EITC refund conditional on working in our sample $(\$ 1,075)$. The right scale in Panel B is chosen to match the scale of Panel A so that the size of the extensive margin response is scaled in the same units. The best-fit lines and standard errors are estimated as in Figure 8. 